\title{
MANAGING STRATEGIES OF PRODUCT QUALITY AND PRICE BASED ON TRUST UNDER DIFFERENT POWER STRUCTURES
}

\author{
Xiao Fu ${ }^{1}$, Shuchun Liu ${ }^{1}$, Wendi Shen ${ }^{2}$ And Guanghua Han ${ }^{3, *}$
}

\begin{abstract}
This paper investigates the quality and pricing decisions in a supply chain consists of one retailer and two manufacturers. The retailer updates the trust value to manufacturers based on the historical information of product quality to determine the actual order quantity. We propose four game models by considering two situations, i.e., manufacturer-dominant scenario and retailer-dominant scenario. Based on theoretical and numerical analysis, we obtain a series of valuable management insights. For example, when a manufacturer with unreliable product quality is the leader and competes with another reliable manufacturer, the retailer's profit would eventually surpass that of two stronger manufacturers. When the retailer is the leader, the retailer's profit is often greater when two manufacturers engage in the Stackelberg game rather than that in Bertrand game, and the manufacturer with unreliable product quality can make profit no less than that of another manufacturer with reliable quality.
\end{abstract}

Mathematics Subject Classification. 90B06.

Received August 11, 2020. Accepted February 28, 2021.

\section{INTRODUCTION}

Retail industry profoundly impacts the society in both developed and developing economies all over the word. According to the Digital Commerce [8], the total retail sales increased 3.8\% in 2019 to $\$ 3.763$ trillion dollars, contributes $17.5 \%$ of US GDP. At the same time, China's retail sales of customer goods valued at 41.16 trillion yuan rose 8 percent year-on-year in 2019 [32]. Among the supply chains in retail industry, the retailers and manufacturers contribute sales by selling channels and producers, respectively. Some large retailers such as Wal-Mart, Carrefour, Best Buy, etc. hold the dominant position in the supply chain, which is named as retailer-dominated supply chain. Meanwhile, some powerful manufacturers (e.g., s Dell, Procter \& Gamble, Nike, etc.) enable to dominate supply chains, which is called manufacturer-dominated supply chain. The leadership between the retailers and manufacturers determines the interactions among them, and conversely affects the performance of the supply chain as well as the industry.

Keywords. Supply chain management, trust, dynamic update, game theory, simulation.

1 Zhejiang Informatization Development Institute, Hangzhou Dianzi University, Hangzhou 310018, P.R. China.

2 School of Electronic Information and Electrical Engineering, Shanghai Jiao Tong University, Shanghai 200240, P.R. China.

3 School of International and Public Affairs, Institute of Health Yangtze River Delta, China Institute for Urban Governance, Shanghai Jiao Tong University, Shanghai 200030, P.R. China.

*Corresponding author: hanguanghua@sjtu.edu.cn 
Since customers' willingness-to-pay is determined by many factors, among which product quality is a pivotal determinant. Due to today's competitive market, retailers negotiate against manufacturers for advantaged production quality with exceptional price. In practice, retailers partly refer to historical product information to estimate the product quality in orders. The reliance on historical information enable to be denote as trust [30]. The retailer's trust value directly affects manufacturer's profit and the extent to which the retailer trusts the manufacturer in the future transaction. At the same time, the manufacturer's product quality and pricing decision have always been the focus of market competition. An enterprise can only attract and remain customers by providing better product quality and more reasonable price than other competitors [1]. Therefore, this paper studies the trust-based product quality and price competition between retailer and manufactures by analyzing four game situations of Bertrand game and Stackelberg game when manufacturer or retailer is in the dominant position respectively.

Given the dual-tier supply chain of two manufacturers and one retailer, this paper considers the retailer purchase same type of product. But the product quality of two manufacturers is slightly different, the retailer tends to have different order quantity for the two manufacturers and updates trust to manufacturers based on previous historical information on manufacturer quality. Moreover, considering two manufacturers are in a strong and weak relationship in the market, and this is analyzed through the Bertrand game and the Stackelberg game. A Stackelberg game in which one player makes a decision first and the other makes a decision later is also called a leader-follower game. It is a dynamic game process, the status of participants is not consistent, the follower's strategy choice depends on the leader's strategy choice, and finally achieves Nash equilibrium [36]. In Bertrand game, the position of each participant is the same. Moreover, the two parties involved in Bertrand game produce homogeneous products, and there is no collusion, but competition through price. This paper uses the retailer's trust update model towards manufacturers to study the impact of product quality and pricing decision on trilateral profit under different supply chain power structure.

The main contributions of this study are twofold. First, we explore supply chain decisions within multiperiod transactions within four different supply chain power structures. Second, we analyse decision processes considering retailer's perception of trust. Therefore, we employ historical quality information to formulate a trust-updating model, and analytically explore how trust affects decision makers' decision in multiple periods. The optimal decisions considering trust and power structure in supply chain are explored in the following context.

\section{Prior Literature AND MAIN ASSUmptions}

\subsection{Literature review}

Previous studies on product quality and pricing issues focus on parallel competition decisions between multiple single-tier enterprises of replaceable products [1]. In recent years, there has been research on the analysis of product quality and market pricing from the perspective of game decision-making in a dual-tier supply chain system $[3,7,9,16,17]$. Gurnani et al. [19] studied the quality inputs of suppliers and sales efforts and the retail pricing optimization decision of retailers under a variety of different game structures by assuming the product market demand as a linear function of its quality, retail price, and retailing sales effort. Confronted with market risks, Zhu et al. [38] considered designing a product and owning the buyer of the brand but outsourcing the production to the supplier. They also studied the effect of quality investment based on brand reputation on the supplier's production batch decision and the impact of the retailer's order quantity decision. Xie et al. [37] studied the impact of decision makers' risk aversion in three different game structures, vertical integration, manufacturer Stackelberg and supplier Stackelberg in the supply chain system comprising component suppliers and finished product manufacturers, on product quality investment and retail pricing decisions in the end market. Chen et al. [5] analysed whether a direct sales channel must be introduced into a traditional retailing channel and the impact of channel introduction on quality and pricing decision. Giri et al. [18] studied study the product quality and pricing issue in a closed-loop supply chain. Manna et al. [27,28] and Khara et al. [24] established an economic output (EPQ) model with incomplete production system and advertising-dependent 
demand. The advertising rate is assumed to be a function related to time. Two types of inspection errors are considered in the product inspection process.

In most supply chains, the research is on product quality and pricing issues and the decision-making goal merely focuses on maximize profit, which discord with the information sharing and mutual benefit highlighted by the current supply chain. In recent years, an increasing number of empirical studies found that decision makers in the supply chain often express the need to be trusted $[2,20,31,34]$. They are concerned not only about their own profits but also the long-term development of supply chain cooperation, both of which are inseparable from a trust relationship [21,23,25]. Therefore, some scholars have tried to establish a model from the perspective of trust to study the decision-making in supply chain enterprises. Özer et al. [30], after constructing a dual-tier supply chain model, found that the manufacturer's information screening process based on trust $\mathrm{s}$ is a powerful tool for effective production setting, noting that the root cause of cooperation is trust and reliability. EbrahimKhanjari et al. [11] studied the change in profits caused by a retailer's incomplete trust in the demand forecast information in a seller's supply chain. A seller's decision-making behaviour affects her direct economic profits and her future reliability. Fu et al. [14] studied the trust relationship between agent and retailer in the case of multi-period transactions. They analysed the impact of the agent's recommended order quantity on the retailer's trust value based on an enthusiastic or selfish agent. Dubey et al. [10] used empirical analysis to evaluate 250 manufacturing companies in a resource-based view and provided a more nuanced idea of the flexibility, visibility, cooperation, trust and behavioural uncertainty in the supply chain.

Scholars have made many achievements in the study of classical Stackelberg game and Bertrand game. Edalatpanah [12] used Nash-Stackelberg game to obtain the optimal pricing strategy. Xie et al. [37] considered the risk-averse behavior of the players in three different supply chain strategies: Vertical Integration, Manufacturer's Stackelberg and Supplier's Stackelberg. Jafari et al. [22] investigated newsvendor problem for a dyadic supply chain in which both the supplier and the retailer are concerned with Nash bargaining and Stackelberg game. $\mathrm{Ma}$ and $\mathrm{Li}[26]$ constructed dynamic Bertrand-Stackelberg pricing models including two manufacturers and a common retailer in a risk-averse supply chain with the uncertain demand. There are also some literatures related to product quality and pricing involving game theory. Maiti and Giri [29] discussed that in a closed-loop supply chain, manufacturers produce products with acceptable quality to customers and sell products through retailers. They constructed five different scenarios - centralized, decentralized or Nash game as well as three different Stackelberg games, which are led by the manufacturer, retailer and third party respectively. Chakraborty et al. [4] studied how a retailer and each of two competing manufacturers can be beneficial under the strategy of improving collaborative product quality in the supply chain. Two competing manufacturers make investment in their respective product to improve quality and a common retailer sells substitutable products with higher quality to the end customers. They dealt with mainly three different contract scenarios based on the framework of game theory. Taleizadeh et al. [33] aimed to investigate the pricing strategies as well as product quality and decision-making of manufacturer, retailer, and third party operated in two types of closed-loop supply chains. On the basis of these different structures, Stackelberg game model with two manufacturer is developed to explore the maximum value for price, product quality, sales volume (Tab. 1).

This study formulate the decision processes of a dual-tier supply chain which consists of a retailer and two supply manufacturers. After that, we explore how supply chain partners decides their optimal product quality and price considering the retailer's perception of trust on product quality. There exists at least four supply chain power structures, our decisions are made under each supply chain power structure.

\subsection{Research assumptions}

The optimal decisions considering the retailer's trust are explored in multiple transaction periods. In the supply chain we considered, we assume two manufacturers produce the same type of product but with different product quality. The main notations are presented in Table 2 .

Before purchasing products, the retailer relies on historical quality information to prejudge the product quality and update the reliance level after receiving the product. Refer to some prior studies [30], we deem the reliance on historical information as trust. The assumptions are listed as below. 
TABLE 1. Comparison of related literature.

\begin{tabular}{lllllll}
\hline \hline Paper & $\begin{array}{l}\text { Simulation } \\
\text { scenarios }\end{array}$ & $\begin{array}{l}\text { Demand } \\
\text { function }\end{array}$ & Channels & $\begin{array}{l}\text { Decision- } \\
\text { making } \\
\text { multi-period } \\
\text { transaction }\end{array}$ & $\begin{array}{l}\text { Historical } \\
\text { in } \\
\text { product } \\
\text { quality }\end{array}$ & $\begin{array}{l}\text { Trust } \\
\text { factor }\end{array}$ \\
\hline $\begin{array}{l}\text { Maiti } \text { et al. } \text { [29] } \\
\text { Cheng } \text { et al. } \text { [6] }\end{array}$ & $\begin{array}{l}\text { Nash + Stackelberg } \\
\text { Control quality } \\
\text { method }\end{array}$ & $\begin{array}{l}\text { Linear } \\
\text { Random }\end{array}$ & $\begin{array}{l}\text { Single } \\
\text { Single }\end{array}$ & $\begin{array}{l}\text { No } \\
\text { No }\end{array}$ & Yes & No \\
$\begin{array}{l}\text { Chakraborty } \text { et al. } \text {. } \\
{[4]}\end{array}$ & Contract & Linear & Dual & No & No & No \\
$\begin{array}{l}\text { Taleizadeh } \text { et al. } \\
{[33]}\end{array}$ & Stackelberg & Linear & Dual & No & Yes & No \\
$\begin{array}{l}\text { Ebrahim-Khanjari } \text { [11] } \\
\text { This study }\end{array}$ & No & Random & Single & Yes & No & Yes \\
& Bertrand & Linear & Dual & Yes & Yes & Yes \\
\hline
\end{tabular}

TABLE 2. Main notations.

\begin{tabular}{lll}
\hline \hline \multirow{2}{*}{$\begin{array}{l}\text { Basic } \\
\text { Information }\end{array}$} & $\widetilde{d_{n}}:$ The total market demand in the in the $n$th period; \\
& $\widetilde{q}:$ The minimum product quality requirement, $i . e .$, the acceptable quality; \\
\cline { 2 - 3 } & Manufacturer $M_{i}, i=1,2$ & Retailer $R$ \\
\cline { 2 - 3 } & $c_{i}:$ Fixed production cost for manufacturer & \\
& $i ;$ & \\
\hline Decision & $p_{i, n}^{m}:$ The wholesale price set by manufac- & $p_{n}^{r}:$ The wholesale price set by manufac- \\
making & turer $i$ in the $n$th period; & turer in the $n$th period and $p_{n}^{r}>p_{i, n}^{m}>c_{i} ;$ \\
variables & & $d_{i, n}:$ The actual order quantity reported \\
& & by the retailer to manufacturer $i$ in the $n$th \\
& & period; \\
& & $T_{i, n}:$ The retailer's trust value toward man- \\
& & ufacturer $i$ in the $n$th period; \\
\hline Target & $\prod_{n}^{M_{i}}\left(p_{i, n}^{m}\right):$ The manufacturer $i$ profit in & $\prod_{n}^{R}\left(p_{n}^{r}\right):$ The retailer profit in the $n$th \\
function & the $n$th period. & \\
\hline
\end{tabular}

(1) Two manufacturers produce the same type of product.

(2) Customers have a tolerated product quantity. The customer's minimum product quality requirement is $\widetilde{q}$. When the product quality from manufacturer is less than $\widetilde{q}$, the customer considers is as defective product.

(3) Without loss of generality, we assume market demand for products are affected by both product selling price and quality.

(4) Trust is a response to product quality, and the product quality affect the retailer's trust on the manufacturer. The trust value $t$ ranges from 0 to 1 , which means $t=1$ when the retailer fully trust the manufacturer.

(5) The retailer's trust to the manufacturer will affect the order quantity in the next trading period.

\section{Model COnstruction}

This paper studies a dual-tier supply chain consisting of one retailer (she) and two manufacturers (he). The basic decision-making process for the supply chain is shown as follows (Fig. 1): (1) The market determines the total demand based on the retail price and qualified product of the previous period and reports to the retailer. 


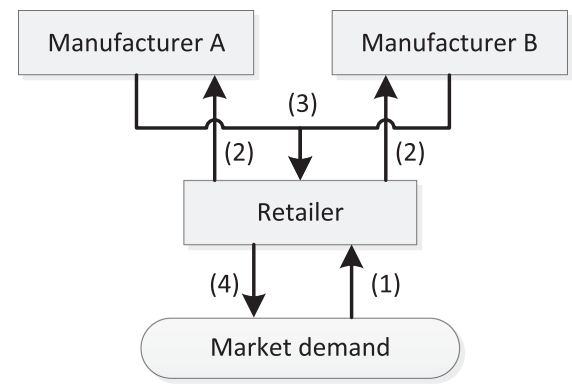

FigURE 1. Supply chain decision-making flow chart for one retailer and two manufacturers.

(2) Retailer determines the actual order quantity based on the trust on the manufacturers' product quality. (3) Manufacturers set the wholesale price based on respective strategies. (4) Retailer determines the uniform retail price based on the manufacturers' wholesale prices and updates the trust value according to the actual product quality in the current period.

\subsection{Trust-based retailer order quantity model}

This paper assumes that market demand is related to price and quality $[1,5,37]$. In the $n$th period, the market forecast demand for manufacturer $i$ 's product is

$$
\widetilde{d_{i, n}}=a_{i}-\beta p_{n}^{r}+\alpha \widetilde{q}
$$

where $a_{i}$ is the potential market demand for the product from manufacturer $M_{i}(i=1,2)$. $\alpha$ and $\beta$ are the influence factors of product quality and price on market demand respectively. $p_{n}^{r}$ indicates the uniform retail price set by the retailer in the $n$th period.

Retailers have two manufacturer channels to order products to meet the total market demand, namely, $\widetilde{d_{n}}=\widehat{d_{1, n}}+\overline{d_{2, n}}$. Because of the different product quality between the two manufacturers, the retailer judges the manufacturers' trust value based on the historical product quality and then selectively purchases products from both manufacturers to determine the actual order quantity.

It is assumed that the actual order quantity purchased in the $n$th period by the retailer from M1 is $d_{1, n}$, which is not in line with the expected market demand for M1 products $\widetilde{d_{1, n}}$ [11]. Such a deviation is related to the retail trust towards both manufacturers [15]. We use $\varepsilon_{1}\left(T_{1, n}, T_{2, n}\right)$ to represent the deviation function:

$$
\varepsilon_{1}\left(T_{1, n}, T_{2, n}\right)=-\frac{T_{2, n}}{T_{1, n}+T_{2, n}} \widetilde{d_{1, n}}+\frac{T_{1, n}}{T_{1, n}+T_{2, n}} \widetilde{d_{2, n}}
$$

where $T_{1, n}$ represents the retailer's trust value towards M1, and $T_{2, n}$ represents the retailer's trust value towards M2. $T_{1, n}, T_{2, n} \in[0,1], 0$ means total distrust, 1 means full trust.

Thus the actual retailer order quantity $d_{1, n}$ from M1 is

$$
d_{1, n}=\widetilde{d_{1, n}}+\varepsilon_{1}\left(T_{1, n}, T_{2, n}\right) .
$$

Similarly, the deviation function between actual order quantity $d_{2, n}$ purchased in the $n$th period by the retailer from M2 and expected market demand $\widetilde{d_{2, n}}$ is $\varepsilon_{2}\left(T_{1, n}, T_{2, n}\right)$; thus the actual retailer order quantity $d_{2, n}$ from M2 is

$$
d_{2, n}=\widetilde{d_{2, n}}+\varepsilon_{2}\left(T_{1, n}, T_{2, n}\right) .
$$

Since the total market demand is the same as the actual retailer order quantity, $\widetilde{d_{n}}=\widetilde{d_{1, n}}+\widetilde{d_{2, n}}=d_{1, n}+d_{2, n}$. So

$$
\varepsilon_{2}\left(T_{1, n}, T_{2, n}\right)=-\varepsilon_{1}\left(T_{1, n}, T_{2, n}\right) .
$$




\subsection{Manufacturer and retailer profits model}

To meet the market quality requirement, manufacturers must invest additional costs in product quality. It is assumed that the input cost for additional product quality by manufacturer $M_{i}(i=1,2)$ is $\frac{\gamma_{i}}{2} q_{i}^{2}$, where $\gamma_{i}$ is the technical cost coefficient for the manufacturer to improve product quality, and $q_{i}$ is the manufacturer's actual product quality.

In the $n$th period, the profit function for manufacturer $M_{i}$ is

$$
\prod_{n}^{M_{i}}\left(p_{i, n}^{m}\right)=\left(p_{i, n}^{m}-c_{i}\right) d_{i, n}-\frac{\gamma_{i}}{2} q_{i}^{2}
$$

where $p_{i, n}^{m}$ represents the wholesale price established by the manufacturer; $c_{i}$ is the fixed cost for the manufacturer; and $d_{i, n}$ is the actual order quantity purchased by the retailer from the manufacturer.

In the $n$th period, the retailer profit function is

$$
\pi_{n}^{R}\left(p_{n}^{r}\right)=\left(p_{n}^{r}-p_{1, n}^{m}\right) d_{1, n}+\left(p_{n}^{r}-p_{2, n}^{m}\right) d_{2, n}
$$

where $p_{n}^{r}$ represents the uniform retail price set by the retailer.

\subsection{Trust update model in multiple period}

The manufacturer is able to know product quality in the current period, but the retailer only knows the actual product quality based on user feedback after the transaction. Therefore, we update the retailer's trust value towards the manufacturer by establishing judgement function $F(q, n)$ as follows:

$$
F q, n=\left\{\begin{array}{l}
\theta_{g} e^{\tau n}, q \geq \widetilde{q} \\
\theta_{l} e^{\tau n}, q<\widetilde{q}
\end{array}\right.
$$

where $\theta_{g}$ represents the trust increase coefficient while $\theta_{l}$ represents the trust decrease coefficient, $\theta_{g} \in(0,1), \theta_{l} \in$ $(-1,0)$ and $\theta_{g}<\left|\theta_{l}\right|$. This means that when product quality is good enough, it is a long-term accumulation process for the manufacturer to gain the retailer's trust, but an unqualified product is more likely to let the retailer lose trust rapidly $[11,30]$.

$\tau$ is a time constant representing the decay rate of trust increase and decrease coefficients, and $\tau>0$. The larger $\tau$ is, the faster the trust coefficient decays. In the actual transaction, as the number of transactions increases, the retailer's trust value towards the manufacturer tends to stabilize according to historical experience, so we assume that the trust increase and decrease coefficients gradually diminish and tend to be stable with increased transaction frequency [30].

On the basis of the retailer's trust towards manufacturer $M_{i}(i=1,2)$ in the previous period, the retailer updates trust value towards the manufacturer according to the judgement function equation (3.8) [15],

$$
T_{i, n}= \begin{cases}T_{i, n-1}+F\left(q_{i, n-1}, n-1\right) \times\left(1-T_{i, n-1}\right), & q_{i, n-1} \geq \widetilde{q} \\ T_{i, n-1}+F\left(q_{i, n-1}, n-1\right) \times T_{i, n-1}, & q_{i, n-1}<\widetilde{q}\end{cases}
$$

where $T_{i, n}$ represents the retailer's trust value towards manufacturer $i$ in the $n$th period, and $q_{i, n-1}$ represents the manufacturer's product quality in the $n-1$ th. $1-T_{i, n-1}$ means a trust increase range in the $n$th period, and $T_{i, n-1}$ means a trust decrease range in the $n$th period.

Proposition 3.1. If $\forall T_{i, n-1} \in(0,1)$, then $\forall T_{i, n} \in(0,1)$, that is, the trust value will not exceed the limit.

Proof. First, prove that the upper limit of the trust value does not exceed 1 , and trust increase $0<\left(1-T_{i, n-1}\right)<$ 1.

In the trust update model, if $T_{i, n}=T_{i, n-1}+\theta_{g} e^{-\tau n}\left(1-T_{i, n-1}\right)<1$ needs to be proved, we need only prove $\theta_{g} e^{-\tau n}<1$. 
Since the trust increase coefficient $\theta_{g} \in(0,1)$, when $n \geq 1$, and $n \in Z$ (integer set), the time constant $\tau>0$, we can get $e^{-\tau n} \leq 1$, thus obtaining $0<\theta_{g} e^{-\tau n}<1$, showing that the upper limit of trust value does not exceed 1.

Second, prove that the lower limit of the trust value is not less than 0 , and the trust decrease $0<T_{i, n-1}<1$.

In the trust update model, if $T_{i, n}=T_{i, n-1}+\theta_{l} e^{-\tau n} T_{i, n-1}>0$ needs to be proved, we need only prove $\theta_{l} e^{-\tau n}>-1$.

Since the trust decrease coefficient $\theta_{l} \in(-1,0)$, when $n \geq 1$, and $n \in Z$ (integer set), the time constant $\tau>$ 0 , we can get $e^{-\tau n} \leq 1$, thus obtaining $-1<\theta_{l} e^{-\tau n}<0$, showing that the lower limit of trust value is no less than 0 . Proof ends.

\section{Analysis of optimal Wholesale price AND Retail PRice}

There exist different market advantage position among manufacturers in competition. Comparing with the advantaged manufacturer, the disadvantaged manufacturer decides its decisions based on the advantaged manufacturer. In this paper, we consider two competitive manufactures to supply a retailer. The decisions process between two manufacturers with different advantages is able to be formulated by a Stackelberg game model. However, when two manufacturer has the same advantage in market, the decisions process between them enable to be formulated by a Bertrand game model. In sum, there exist two different game processes in two supply chain power structures. We thereby solve the research questions with four different models.

Therefore, we discuss the supply chain in two aspects: (1) the manufacturers are the leaders and the retailer is the follower, and (2) The retailer is the leader and the manufacturers are the followers. For example, in order to avoid monopoly, if the retailer's trust towards one of the manufacturers is 0 , the actual order quantity is 0 . In this case, the retailer cannot judge whether the manufacturer's product quality is acceptable in the next trading period. The retailer's trust towards the manufacturer cannot be updated. Thus in this section, we assume that $T_{1, n}, T_{2, n} \neq 0$ to guarantee that the retailer can always order products from both manufacturers.

\subsection{Manufacturer-dominant supply chain}

In the case of a manufacturer-dominant supply chain, the retailer first updates the trust value based on historical information on the manufacturer's product quality to determine her actual order quantity from both manufacturers. When the manufacturer's wholesale price is determined, she can only maximize profit by adjusting the retail price. When manufacturers are the leaders and the retailer is the follower, this scenario can be divided into two types of games for discussion:

(1) A Bertrand game between M1 and M2, that is, two manufacturers make decisions simultaneously. In the $n$th period, the retailer first sets the retail price as $p_{n}^{r}$, then M1 determines the wholesale price $p_{1, n}^{m}$ and M2 determines the wholesale price $p_{2, n}^{m}$.

(2) A Stackelberg game between M1 and M2, that is, in the two manufacturers, the manufacturer $i$ dominates is the leader and the manufacturer $j$ is the follower. In the $n$th period, the retailer first sets the retail price $p_{n}^{r}$, then $M_{j}$ first determines the wholesale price $p_{j, n}^{m}$ before $M_{i}$ determines the wholesale price $p_{i, n}^{m},(i, j=$ $1,2, i \neq j)$.

The retailer determines the retail price to maximize profit by observing the wholesale prices from both manufacturers. By backward induction, we first obtain the response function of the retail price from retailer. The response function of the retail price from retailer given the conditions of $p_{1, n}^{m}$ and $p_{2, n}^{m}$ is as follows:

$$
p_{n}^{r *}\left(p_{1, n}^{m}, p_{2, n}^{m}\right)=\frac{A_{1}}{4 \beta}+\frac{T_{1, n}}{2\left(T_{1, n}+T_{2, n}\right)} p_{1, n}^{m}+\frac{T_{2, n}}{2\left(T_{1, n}+T_{2, n}\right)} p_{2, n}^{m}
$$

where $A_{1}=a_{1}+a_{2}+2 \alpha \widetilde{q}$. 
Corollary 4.1. In a manufacturer-dominant situation, the optimal retail price is positively correlated with the wholesale price.

Proof. After calculating the first order derivation of equation (4.1), we have the following formulation.

$$
\frac{\partial p_{n}^{r *}\left(p_{1, n}^{m}, p_{2, n}^{m}\right)}{\partial p_{1, n}^{m}}=\frac{T_{1, n}}{2\left(T_{1, n}+T_{2, n}\right)}>0, \frac{\partial p_{n}^{r *}\left(p_{1, n}^{m}, p_{2, n}^{m}\right)}{\partial p_{2, n}^{m}}=\frac{T_{2, n}}{2\left(T_{1, n}+T_{2, n}\right)}>0 .
$$

Because two formulations are positive values, we have Corollary 4.3. Proof ends.

According to equation (4.1), the optimal retail price from the retailer is positively correlated with the manufacturer's wholesale price. It is also affected by the retailer's trust value towards both manufacturers. The greater the retailer's trust value towards manufacturer $i$, the more likely the retailer's optimal retail price will be affected by the manufacturer's wholesale price fluctuation.

\subsubsection{Scenario 1: Bertrand Game between M1 and M2}

Backward induction is used to obtain the retailer's reaction function equation (4.1). Two manufacturers make decisions at the same time to determine their own optimal wholesale price to maximize their own profits. The optimal wholesale price of both manufacturers $p_{i, n}^{m^{*}}$ is:

$$
p_{i, n}^{m^{*}}=\frac{A_{1}}{6} \frac{T_{i, n}+T_{j, n}}{T_{i, n}}+\frac{2 c_{i}}{3}-\frac{T_{j, n}}{T_{i, n}} \frac{c_{j}}{3},(i, j=1,2, i \neq j) .
$$

Proof. Substituting equations (3.1)-(3.5) and (4.1) into M1 profit function equation (3.6) and deriving the wholesale price $p_{1, n}^{m}$, we can obtain

$$
\begin{aligned}
d_{i, n} & =\left[a_{1}+a_{2}-2 \beta\left(\frac{A_{1}}{4}+\frac{T_{i, n}}{2\left(T_{i, n}+T_{j, n}\right)} p_{i, n}^{m}+\frac{T_{j, n}}{2\left(T_{i, n}+T_{j, n}\right)} p_{j, n}^{m}\right)+2 \alpha \widetilde{q}\right] \frac{T_{i, n}}{T_{i, n}+T_{j, n}} \\
\frac{\partial \pi_{n}^{\mathrm{M} 1}\left(p_{1, n}^{m}\right)}{\partial p_{1, n}^{m}} & =\left(a_{1}+a_{2}-2 \beta p_{n}^{r}+2 \alpha \widetilde{\mathrm{q}}\right) \frac{T_{1, n}}{T_{1, n}+T_{2, n}}-\left(p_{1, n}^{m}-c_{1}\right) \beta\left(\frac{T_{1, n}}{T_{1, n}+T_{2, n}}\right)^{2} \\
\frac{\partial^{2} \pi_{n}^{\mathrm{M} 1}\left(p_{1, n}^{m}\right)}{\partial p_{1, n}^{m}{ }^{2}} & =-2 \beta\left(\frac{T_{1, n}}{T_{1, n}+T_{2, n}}\right)^{2}<0 .
\end{aligned}
$$

From equation (4.5), the second derivative of manufacturer profit function on wholesale price is less than 0 , so the retail price has a maximum value. Let equation (4.4) equal 0 , we can obtain

$$
p_{1, n}^{m}=\frac{A_{1}}{4} \frac{T_{1, n}+T_{2, n}}{T_{1, n}}-\frac{1}{2} \frac{T_{2, n}}{T_{1, n}} p_{2, n}^{m}+\frac{c_{1}}{2} .
$$

Similarly, we can obtain

$$
p_{2, n}^{m}=\frac{A_{1}}{4} \frac{T_{1, n}+T_{2, n}}{T_{2, n}}-\frac{1}{2} \frac{T_{1, n}}{T_{2, n}} p_{1, n}^{m}+\frac{c_{2}}{2} .
$$

Equation (4.2) can be obtained by linking equations (4.6) and (4.7) simultaneous. Proof ends.

Substituting equation (4.2) into equation (4.1), the retailer's optimal retail price $p_{n}^{r^{*}}$ is

$$
p_{n}^{r^{*}}=\frac{A_{1}}{12}+\frac{T_{1, n}}{\left(T_{1, n}+T_{2, n}\right)} \frac{c_{1}}{6}+\frac{T_{2, n}}{\left(T_{1, n}+T_{2, n}\right)} \frac{c_{2}}{6} .
$$

Corollary 4.2. When the fixed costs of two manufacturers are the same, the optimal retail price is independent with the retailer's trust value.

Proof. According to equation (4.8), when the fixed cost of two manufacturers' products is the same, that is, $c_{1}=c_{2}$, the optimal retail price of the retailer is constant regardless of her trust in the manufacturers. Proof ends. 


\subsubsection{Scenario 2: Stackelberg game between M1 and M2}

Manufacturer $i$ is the leader and manufacturer $j$ is the follower between two manufacturers. In the $n$th period, manufacturer $M_{j}$ first determines the wholesale price $p_{j, n}^{m}$ and then $M_{i}$ determines the wholesale price $p_{i, n}^{m}(i, j=1,2, i \neq j)$. By backward induction, according to the wholesale price set by the manufacturer $i$, we can obtain the response function of manufacturer $j$ 's wholesale price after obtaining the retailer's reaction function.

The reaction function of manufacturer $j$ 's wholesale price under the given condition of wholesale price $p_{i, n}^{m}$ by manufacturer $i$ is

$$
p_{j, n}^{m^{*}}=\frac{A_{1}}{4} \frac{T_{i, n}+T_{j, n}}{T_{i, n}}-\frac{1}{2} \frac{T_{i, n}}{T_{j, n}} p_{i, n}^{m}+\frac{c_{j}}{2} .
$$

According to equation (4.9), we can obtain

$$
\frac{\partial p_{j, n}^{m}}{\partial p_{i, n}^{m}}=-\frac{1}{2} \frac{T_{i, n}}{T_{j, n}}<0
$$

After obtaining the reaction function of the retailer and of manufacturer $j$, manufacturer $i$ makes the decision to determine his own optimal wholesale price to maximize profits. The optimal wholesale price of manufacturer $i p_{i, n}^{m}$ is

$$
p_{i, n}^{m^{*}}=\frac{A_{1}}{4} \frac{T_{i, n}+T_{j, n}}{T_{i, n}}-\frac{T_{j, n}}{T_{i, n}} \frac{c_{j}}{2}+\frac{c_{i}}{2}
$$

Substituting equation (4.11) into equation (4.9), we can obtain the optimal wholesale price of manufacturer $j p_{j, n}^{m^{*}}$ :

$$
p_{j, n}^{m^{*}}=\frac{A_{1}}{8} \frac{T_{i, n}+T_{j, n}}{T_{j, n}}-\frac{T_{i, n}}{T_{j, n}} \frac{c_{i}}{4}+\frac{3 c_{j}}{4} .
$$

Lastly, substituting equations (4.11) and (4.12) into the retailer response function, we obtain the optimal retail price $p_{n}^{r^{*}}$ :

$$
p_{n}^{r^{*}}=\frac{7 A_{1}}{16}+\frac{T_{i, n}}{\left(T_{i, n}+T_{j, n}\right)} \frac{c_{i}}{8}+\frac{T_{j, n}}{\left(T_{i, n}+T_{j, n}\right)} \frac{c_{j}}{8} .
$$

Corollary 4.3. The wholesale price of manufacturer $i$ decreases by wholesale price of manufacturer $j$.

Proof. It can be seen from equation (4.10) that when the wholesale price of manufacturer $i$ increases, the optimal wholesale price of manufacturer $j$ decreases, the extent of which is related to the retailer's trust ratio towards both manufacturers. Proof ends.

When the retailer's trust ratio to manufacturer $i$ and manufacturer $j$ is greater, this indicates that the retailer is more likely to trust manufacturer $i$, and the optimal wholesale price of manufacturer $j$ decreases when the optimal wholesale price of manufacturer $i$ increases.

\subsection{Retailer-dominant supply chain}

When the retailer is the leader and the manufacturers are the followers, this scenario can be divided into two types of games for discussion:

(1) A Bertrand game between M1 and M2, that is, two manufacturers make decisions simultaneously. In the $n$th period, M1 determines the wholesale price $p_{1, n}^{m}$, M2 determines the wholesale price $p_{2, n}^{m}$, and lastly, the retailer sets the retail price as $p_{n}^{r}$.

(2) A Stackelberg game between M1 and M2, that is, with two manufacturers, the manufacturer $i$ dominates and is the leader and the manufacturer $j$ is the follower. In the $n$th period, $M_{j}$ first determines the wholesale price $p_{1, n}^{m}$, then $M_{i}$ determines the wholesale price $p_{2, n}^{m}$, and lastly, the retailer sets the retail price $p_{n}^{r}$. 


\subsubsection{Greedy function}

In a retailer-dominant case, the retailer must determine her actual order quantity based on the trust value towards the manufacturer's product quality and wholesale price. Therefore, in the retailer-dominant case, we introduce the greedy function $B_{i}\left(p_{i, n}^{m}, p_{j, n}^{m}\right)$ as the retailer's forecast demand deviation caused by the wholesale price set by the manufacturer $M_{i}[1,35]$. The specific form is as follows $(i, j=1,2, i \neq j)$ :

$$
B_{i}\left(p_{i, n}^{m}, p_{j, n}^{m}\right)=-\frac{T_{i, n}}{T_{i, n}+T_{j, n}} p_{i, n}^{m}+\frac{T_{j, n}}{T_{i, n}+T_{j, n}} p_{j, n}^{m} .
$$

Therefore, in the retailer-dominant case, her actual order quantity $d_{i, n}$ to manufacturer $M_{i}$ is

$$
d_{i, n}=\widetilde{d_{i, n}}+v B_{i}\left(p_{i, n}^{m}, p_{j, n}^{m}\right)+\varepsilon_{i}\left(T_{i, n}, T_{j, n}\right)
$$

where $v$ is the greedy coefficient in order to adjust the magnitude between price and demand. We analyse the rationality of adjusting greedy function:

(1) $B_{i}\left(p_{i, n}^{m}, p_{j, n}^{m}\right)+B_{j}\left(p_{i, n}^{m}, p_{j, n}^{m}\right)=0$, so $\widetilde{d_{n}}=\widetilde{d_{1, n}}+\widetilde{d_{2, n}}=d_{1, n}+d_{2, n}$, that is, the total market demand remains unchanged.

(2) The retailer's greedy function solves the monopoly. Even if the retailer's trust in one manufacturer $i$ is reduced to 0 , the actual order quantity $d_{i, n}=v p_{j, n}^{m}$ from manufacturer $i$ prevents manufacturer $j$ from making monopoly, then uncontrollably increasing wholesale price $p_{j, n}^{m}$. This also guarantees that the retailer always has two manufacturers to provide her with products.

\subsubsection{Scenario 3: Bertrand game between $M 1$ and M2}

The retailer determines the optimal retail price $p_{n}^{r^{*}}$ by observing the wholesale prices of two manufacturers. By backward induction, we first determine the reaction function of the wholesale price of both manufacturers at the given retail price $p_{n}^{r}$ :

$$
p_{i, n}^{m^{*}}\left(p_{n}^{r}\right)=\left(\frac{2}{3 v}+\frac{T_{j, n}}{3 v T_{i, n}}\right) A+\frac{2}{3} c_{i}+\frac{1}{3} \frac{T_{j, n}}{T_{i, n}} c_{j}
$$

where $A=a_{1}+a_{2}-2 \beta p_{n}^{r}+2 \alpha \widetilde{q}$ indicates total market demand.

According to equation (4.16),

$$
\frac{\partial p_{i, n}^{m^{*}}}{\partial p_{n}^{r}}=-2 \beta\left(\frac{2}{3 v}+\frac{T_{j, n}}{3 v T_{i, n}}\right)<0 .
$$

Corollary 4.4. In the retailer-dominant case, the optimal wholesale price is negatively correlated with the retail price.

Proof. According to equation (4.17), the manufacturer's optimal wholesale price $p_{i, n}^{m^{*}}$ is negatively correlated with the retail price $p_{n}^{r}$. The optimal wholesale price is influenced by the retailer's trust ratio towards both manufacturers, the influence coefficient of price on market demand and the greedy coefficient. Proof ends.

Substituting equation (4.16) into the retailer profit function equation (3.7) and deriving the retail price, we can obtain the optimal retail price $p_{n}^{r^{*}}$ :

$$
p_{n}^{r^{*}}=\frac{K_{1}}{2 \beta\left(1+K_{1}\right)} A_{1}+\frac{1}{9\left(1+K_{1}\right)}\left(K_{2} c_{1}+K_{3} c_{2}\right)
$$

where $K_{1}=1+\frac{16 \beta}{9 v}+\frac{4 \beta}{9 v}\left(\frac{T_{1, n}}{T_{2, n}}+\frac{T_{2, n}}{T_{1, n}}\right), K_{2}=\frac{2 T_{1, n}^{2}+6 T_{1, n} T_{2, n}+T_{2, n}^{2}}{T_{2, n}\left(T_{1, n}+T_{2, n}\right)}, K_{3}=\frac{2 T_{2, n}^{2}+6 T_{1, n} T_{2, n}+T_{1, n}^{2}}{T_{1, n}\left(T_{1, n}+T_{2, n}\right)}$.

Lastly, substituting the optimal retail price (4.18) into the manufacturer's wholesale price response equation (4.16), we can obtain the manufacturer's optimal wholesale price $p_{i, n}^{m^{*}}$ :

$$
p_{i, n}^{m^{*}}=\left(\frac{2}{3 v}+\frac{T_{j, n}}{3 v T_{i, n}}\right)\left[A_{1}-\frac{K_{1}}{\left(1+K_{1}\right)} A_{1}-\frac{2 \beta}{9\left(1+K_{1}\right)}\left(K_{2} c_{1}+K_{3} c_{2}\right)\right]+\frac{2}{3} c_{i}+\frac{1}{3} \frac{T_{j, n}}{T_{i, n}} c_{j} .
$$




\subsubsection{Scenario 4: Stackelberg game between M1 and M2}

Manufacturer $i$ is the leader and manufacturer $j$ is the follower. In the $n$th period, manufacturer $M_{j}$ first determines the wholesale price $p_{j, n}^{m}$, and then $M_{i}$ determines the wholesale price $p_{i, n}^{m}(i, j=1,2, i \neq j)$. By backward induction, first, according to the retail price set by the retailer and the wholesale price set by manufacturer $i$, obtain the reaction function of the wholesale price of manufacturer $j$, then substitute it into the profit function of manufacturer $i$. Derive $p_{i, n}^{m}$ to obtain the reaction function of the wholesale price of both manufacturers:

$$
\begin{aligned}
& p_{i, n}^{m^{*}}\left(p_{n}^{r}\right)=\left(\frac{1}{2 v}+\frac{T_{j, n}}{4 v T_{i, n}}\right) A+\frac{1}{4} c_{i}+\frac{1}{4} \frac{T_{j, n}}{T_{i, n}} c_{j} \\
& p_{j, n}^{m^{*}}\left(p_{n}^{r}\right)=\left(\frac{5}{8 v}+\frac{T_{i, n}}{4 v T_{j, n}}\right) A+\frac{5}{8} c_{j}+\frac{1}{8} \frac{T_{i, n}}{T_{j, n}} c_{i} .
\end{aligned}
$$

According to equations (4.20) and (4.21)

$$
\frac{\partial p_{i, n}^{m^{*}}}{\partial p_{n}^{r}}=-2 \beta\left(\frac{1}{2 v}+\frac{T_{j, n}}{4 v T_{i, n}}\right)<0, \frac{\partial p_{j, n}^{m^{*}}}{\partial p_{n}^{r}}=-2 \beta\left(\frac{5}{8 v}+\frac{T_{i, n}}{4 v T_{j, n}}\right)<0 .
$$

Therefore, the optimal wholesale prices $p_{i, n}^{m^{*}}, p_{j, n}^{m^{*}}$ are negatively correlated with the retail price $p_{n}^{r}$.

Substitute the reaction function of both manufacturers on the retail price equations (4.20) and (4.21) into the retailer profit function equation (3.7). Deriving the retail price, the retailer's optimal retail price $p_{n}^{r^{*}}$ can be obtained:

$$
p_{n}^{r^{*}}=\frac{B_{1}+B_{2}+B_{3}}{2 \beta\left(1+B_{1}+B_{2}+B_{3}\right)} A_{1}+\frac{B_{4}+B_{5}}{2 \beta\left(1+B_{1}+B_{2}+B_{3}\right)} c_{1}+\frac{B_{6}+B_{7}}{2 \beta\left(1+B_{1}+B_{2}+B_{3}\right)} c_{2}
$$

where

$$
\begin{aligned}
B_{1} & =1+\frac{11 \beta}{16 v}+\frac{\beta}{8 v} \frac{T_{i, n}}{T_{j, n}}+\frac{3 \beta}{16 v} \frac{T_{j, n}}{T_{i, n}} \\
B_{2} & =\left(\frac{35 \beta}{16 v}+\frac{3 \beta}{16 v} \frac{T_{j, n}}{T_{i, n}}\right)\left(\frac{T_{j, n}}{T_{i, n}+T_{j, n}}\right) \\
B_{3} & =\left(\frac{31 \beta}{16 v}+\frac{\beta}{8 v} \frac{T_{i, n}}{T_{j, n}}\right)\left(\frac{T_{i, n}}{T_{i, n}+T_{j, n}}\right) \\
B_{4} & =\frac{5 \beta}{16}+\frac{3 \beta}{16} \frac{T_{j, n}}{T_{i, n}} \\
B_{5} & =\left(\frac{\beta}{2 v} \frac{T_{j, n}}{T_{i, n}}-\frac{3 \beta}{2 v}+\frac{21 \beta}{32}\right)\left(\frac{T_{j, n}}{T_{i, n}+T_{j, n}}\right) \\
B_{6} & =\frac{3 \beta}{16}+\frac{\beta}{16} \frac{T_{i, n}}{T_{j, n}} \\
B_{7} & =\left(\frac{\beta}{2 v} \frac{T_{i, n}}{T_{j, n}}+\frac{\beta}{2 v}+\frac{9 \beta}{32}\right)\left(\frac{T_{i, n}}{T_{i, n}+T_{j, n}}\right) .
\end{aligned}
$$

Lastly, the optimal wholesale price can be obtained by substituting the optimal retail price $p_{n}^{r^{*}}(4.23)$ into the reaction function equations (4.20) and (4.21) of both manufacturers' wholesale prices: 

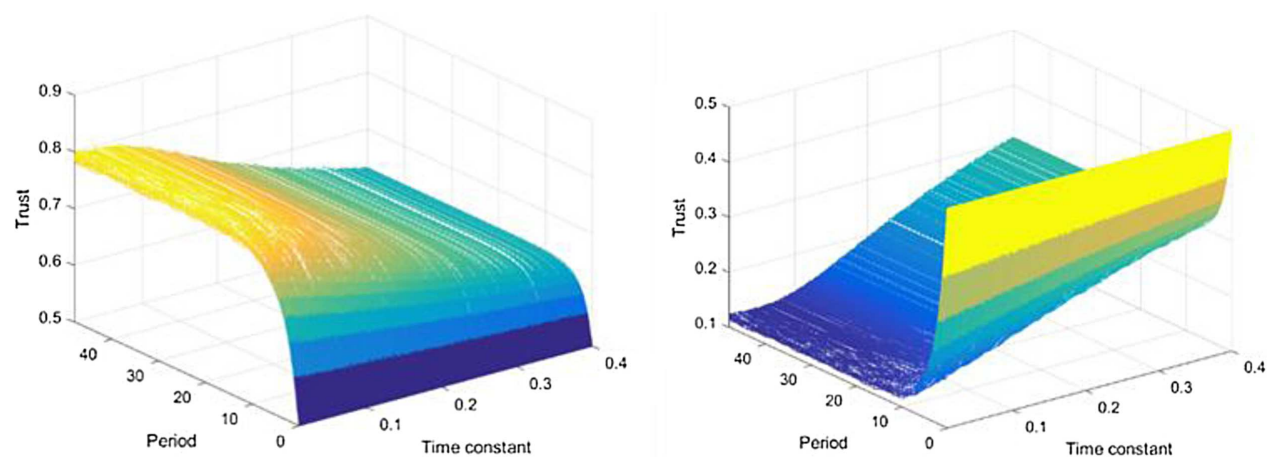

FiguRE 2. Relationship between time constant and trust value.

$$
\begin{aligned}
p_{i, n}^{m^{*}}= & \left(\frac{1}{2 v}+\frac{T_{j, n}}{4 v T_{i, n}}\right)\left(A_{1}-\frac{B_{1}+B_{2}+B_{3}}{\left(1+B_{1}+B_{2}+B_{3}\right)} A_{1}-\frac{B_{4}+B_{5}}{\left(1+B_{1}+B_{2}+B_{3}\right)} c_{1}-\frac{B_{6}+B_{7}}{\left(1+B_{1}+B_{2}+B_{3}\right)} c_{2}\right) \\
& +\frac{1}{4} c_{i}+\frac{1}{4} \frac{T_{j, n}}{T_{i, n}} c_{j} \\
p_{j, n}^{m^{*}}= & \left(\frac{5}{8 v}+\frac{T_{i, n}}{4 v T_{j, n}}\right)\left(A_{1}-\frac{B_{1}+B_{2}+B_{3}}{\left(1+B_{1}+B_{2}+B_{3}\right)} A_{1}-\frac{B_{4}+B_{5}}{\left(1+B_{1}+B_{2}+B_{3}\right)} c_{1}-\frac{B_{6}+B_{7}}{\left(1+B_{1}+B_{2}+B_{3}\right)} c_{2}\right) \\
& +\frac{5}{8} c_{j}+\frac{1}{8} \frac{T_{i, n}}{T_{j, n}} c_{i} .
\end{aligned}
$$

\subsection{Experimental design and sensitivity analysis}

\subsubsection{Experimental design}

To more clearly understand the impact of trust model on the entire supply chain, we set a series of values to analyse the change in the retailer's trust in the manufacturer, and the impact of the change in trust value on the optimal wholesale price, the optimal retail price, and the actual order quantity and profits of various parties in the supply chain in the four supply chain right structure. The specific relevant parameters are set as follows:

The potential market demand for M1 and M2 is $a_{1}=200, a_{2}=200$. The influence coefficient of product quality on market demand $\alpha=1$, and the influence coefficient of price on market demand $\beta=1$. M1 and M2 are technical cost coefficients $\gamma_{1}=2, \gamma_{2}=2$ for improving product quality. The fixed cost of M1 and M2 is $c_{1}=25, c_{2}=25$. The acceptable quality $\widetilde{q}=15$. The trust increase coefficient $\theta_{g}=0.25$, and the trust decrease coefficient $\theta_{l}=-0.35$. The transaction period is $N=48$.

\subsubsection{Sensitivity analysis}

In order to set a suitable time constant $\tau$, it is assumed that the product quality of the manufacturer in each period obeys the normal distribution $G\left(q, \sigma^{2}\right)$, and the product quality of manufacturer $i$ obeys normal distribution $G\left(q_{i}, \sigma_{i}^{2}\right)$ with mean value $q_{i}$ and variance $\sigma_{i}^{2}$. We take $q=17, \sigma^{2}=2$ represents the case when the trust value rises, and $q=13, \sigma^{2}=2$ represents the case when the trust value falls, the time constant $\tau \in[0.01,0.4]$ is simulated respectively, The result is shown in Figure 2 below:

It can be seen from Figure 2 that when the time parameter $\tau=0.05$, the trust value basically stabilizes after the 30th period, which is in line with the trading cycle we set. Therefore, the following experiments set the time parameter $\tau=0.05$ for simulation.

We then carry out sensitivity analysis on the price sensitivity coefficient $\alpha$. The value set of price sensitivity coefficient $\alpha$ is $\alpha \in\{1,2,3,4\}$, and the other parameters remains the same as above. The retailer's order quantity changes between two manufacturers, the price changes between the manufacturer and the retailer, and the profits changes between the three are shown in Figures 3-5. 

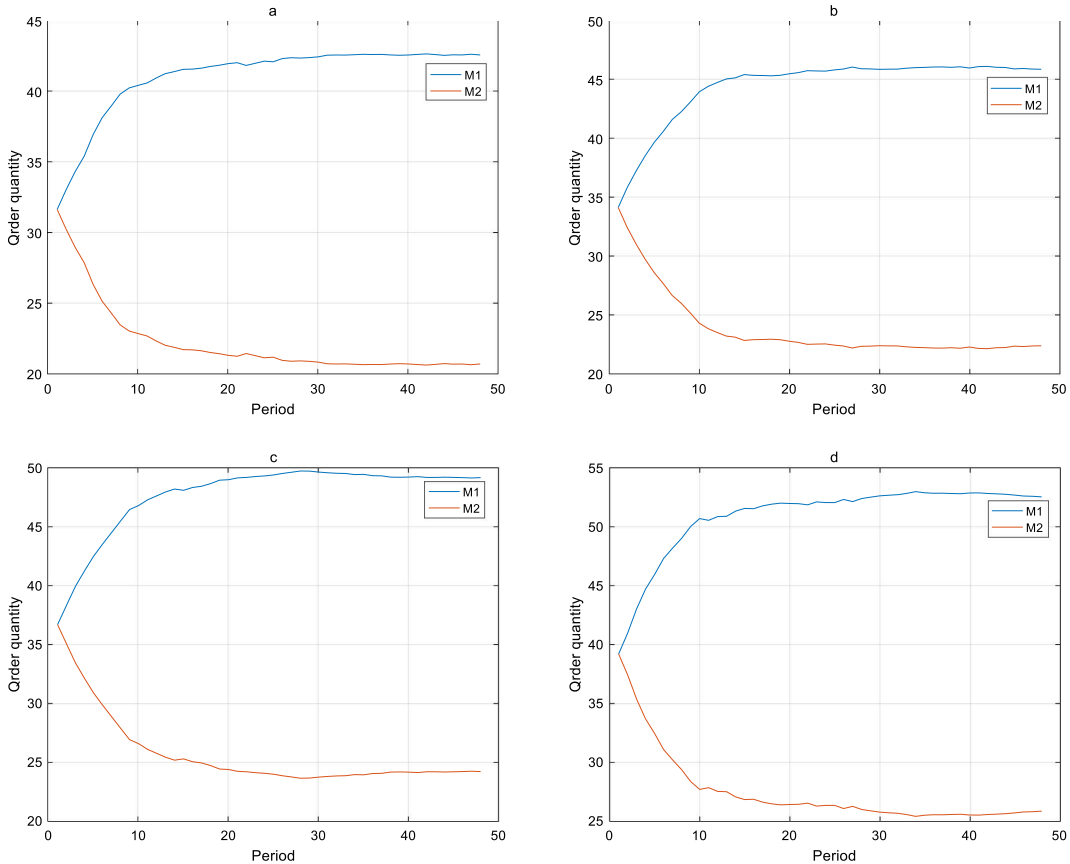

FigURE 3 . The impact of different price sensitivity coefficients $(\alpha=1,2,3,4)$ on retailer's order quantity.
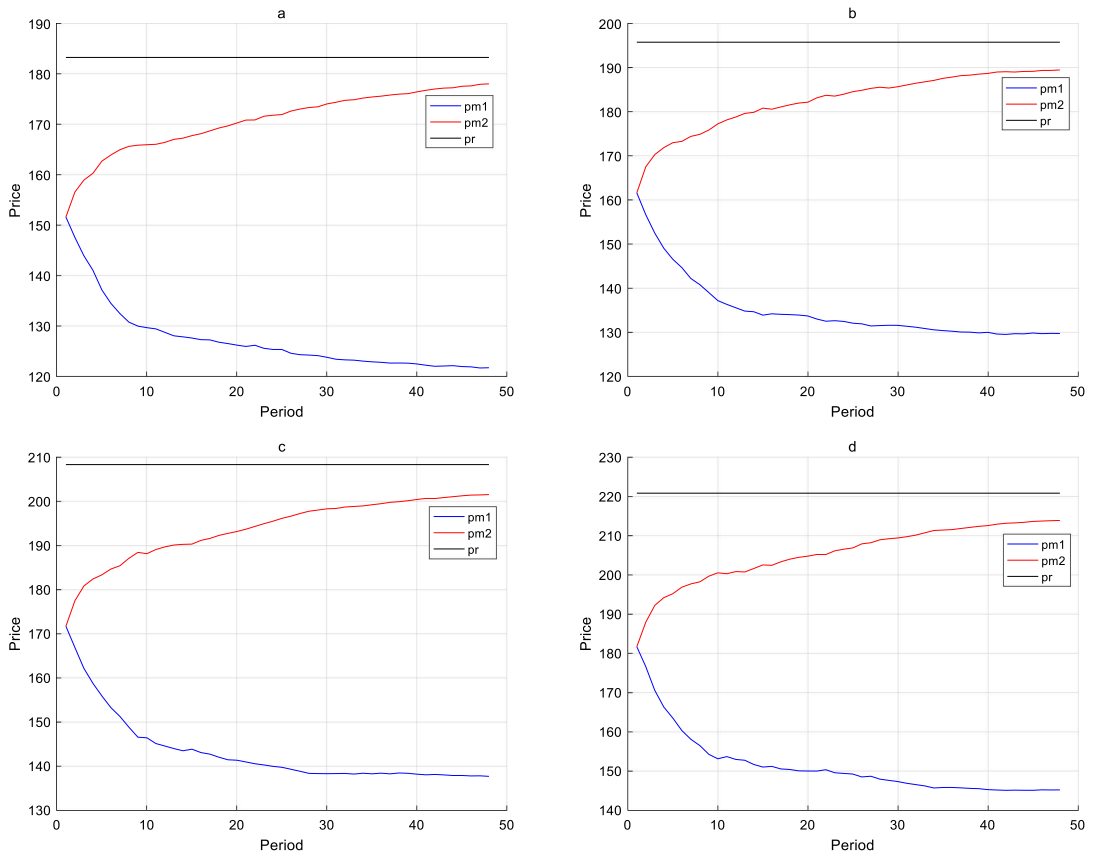

Figure 4 . The impact of different price sensitivity coefficients $(\alpha=1,2,3,4)$ on the pricing of each role. 

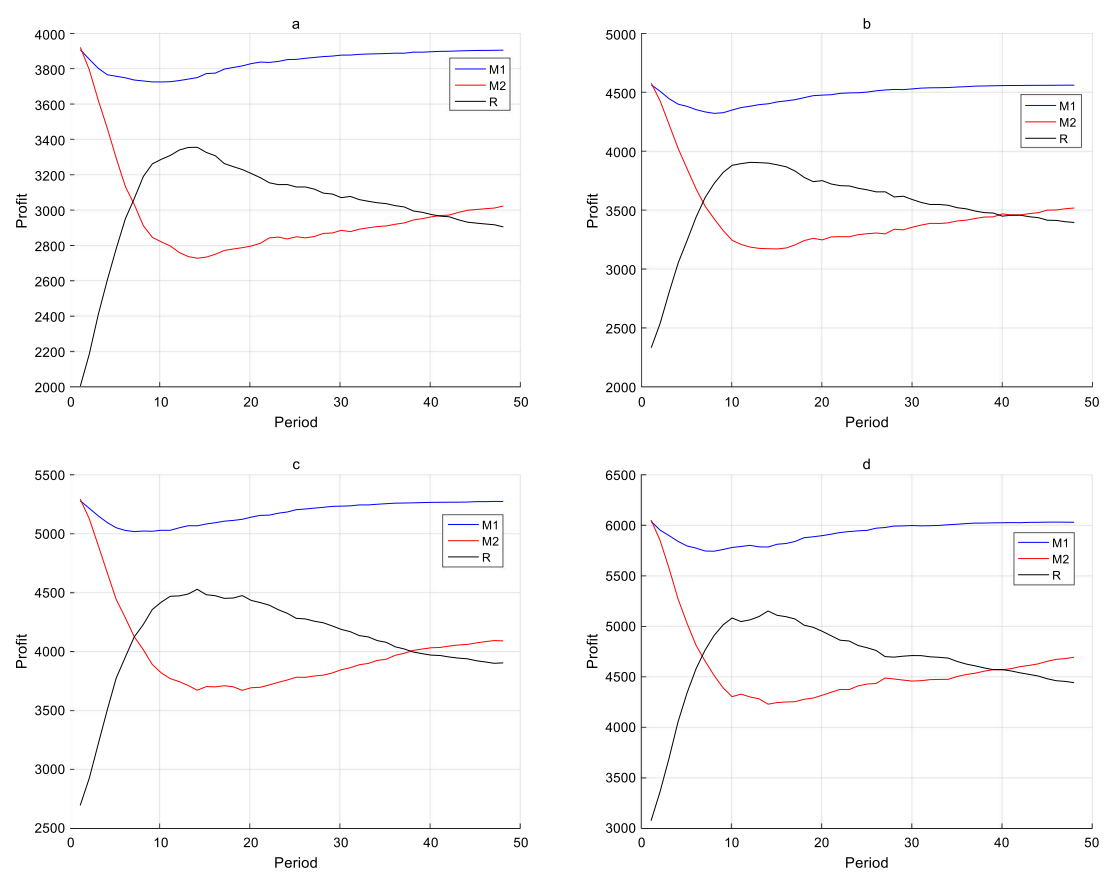

FIgURE 5 . The impact of different price sensitivity coefficients $(\alpha=1,2,3,4)$ on the profits of each role.

We can find that the variation of model parameters does not change the decision-making result of manufacturers and retailers in the context of multi-period trading, that is, the change trend of order quantity, selling price, and profits remains unchanged. From the simulation experiment, we can directly obtain decision results from each role. Therefore, we do not need to do too much sensitivity analysis on other model parameters. This also illustrates the rationality of the trust update model design in this paper.

\section{Simulation Results}

Through the above problem description, model construction, game analysis, and parameter setting, we mainly resort to simulation to analyse the decision-making behaviour of two manufacturers and one retailer in multiperiod transactions when the product quality of both manufacturers is different. The following issues are discussed in detail:

(1) The impact of different product quality of two manufacturers on trust value;

(2) The impact of changes in the retailer's trust to manufacturers on the actual order quantity;

(3) The impact of manufacturer-dominance or retailer-dominance on order quantity, pricing, and profits;

(4) The impact of the Bertrand game or Stackelberg game on the pricing and profits of the three roles in the supply chain.

\subsection{Manufacturers are the leaders, M1 and M2 conducts a Bertrand game}

\subsubsection{Product quality of both manufacturers is reliable}

Set the retailer initial trust value towards two manufacturers as $T_{1,0}=T_{2,0}=0.5$; when the mean value of M1 product quality is $q_{1}=17$ with the variance $\sigma_{1}^{2}=2$, and the mean value of M2 product quality is $q_{2}=16$ 

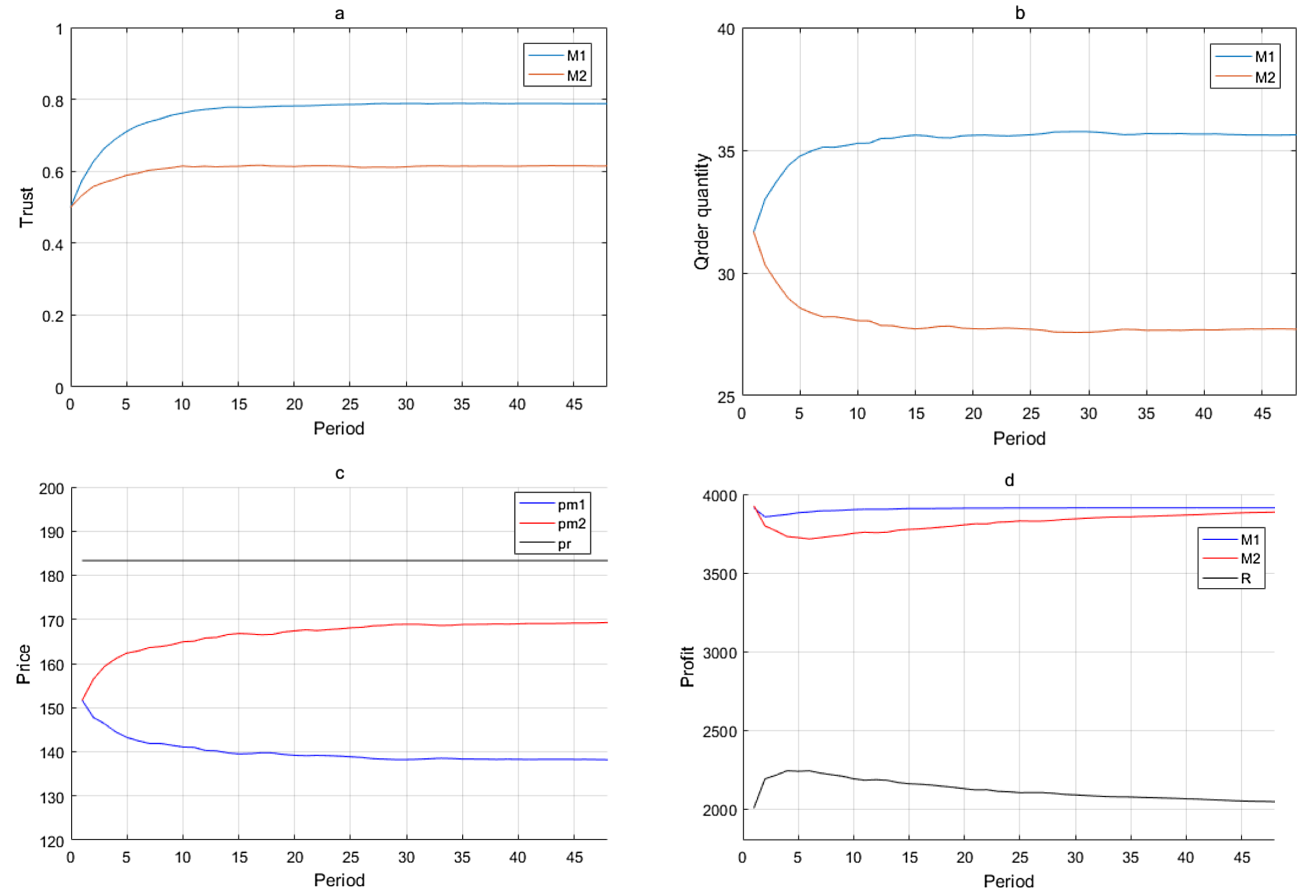

FiguRE 6. Changes in trust, order quantity, pricing, and profit when the product quality of both manufacturers is reliable.

with the variance $\sigma_{2}^{2}=2$, the product quality of both manufacturers is relatively reliable, but the quality of M1 is more reliable than that of M2. The simulation results are shown in Figure 6.

We can see from Figure 6 that the retailer's trust value towards both manufacturers is increasing, but she trusts M1 more, and the increase in M1 trust lasts longer because M1's product quality is more reliable than that of M2. Accordingly, the retailer order quantity for M1 increases while the order quantity for M2 decreases. Since manufacturers are relatively more dominant than retailers, manufacturers can always make more profits than retailers. To increase the retailer's actual order quantity and maintain trust between the two parties, M1 appropriately lowers his wholesale price while M2 increases his wholesale price in order to maintain his own profits. As a result, the profit between the two manufacturers is basically equal in the final calculation.

\subsubsection{Product quality of both manufacturers is unreliable}

Set the retailer initial trust value towards two manufacturers as $T_{1,0}=T_{2,0}=0.5$; when the M1 product quality mean value $q_{1}=14$ with the variance $\sigma_{1}^{2}=2$ and the M1 product quality mean value $q_{1}=13$ with the variance $\sigma_{2}^{2}=2$, the product quality of both manufacturers is unreliable, but the product quality of M1 is relatively more reliable than that of M2. The simulation results are shown in Figure 7.

We can see from Figure 7 that the retailer's trust value towards both manufacturers is declining, and the decline in M2's trust lasts longer because his product quality is less reliable than that of M1. Accordingly, the retailer can only increase the order quantity of M1 and reduce the order quantity of M2, so the profit of M1 is greater than that of M2.

From the change in the retailer's profit and M2 in Figure 7d, it can be clearly seen that although the retailer's profit is increasing at the beginning and M2's profit is decreasing, M2 improves his wholesale price to maintain his own profit due to the manufacturer-dominant situation. Eventually, M2's profit increases and the retailer's profit declines, thus swallowing retailer revenue. 

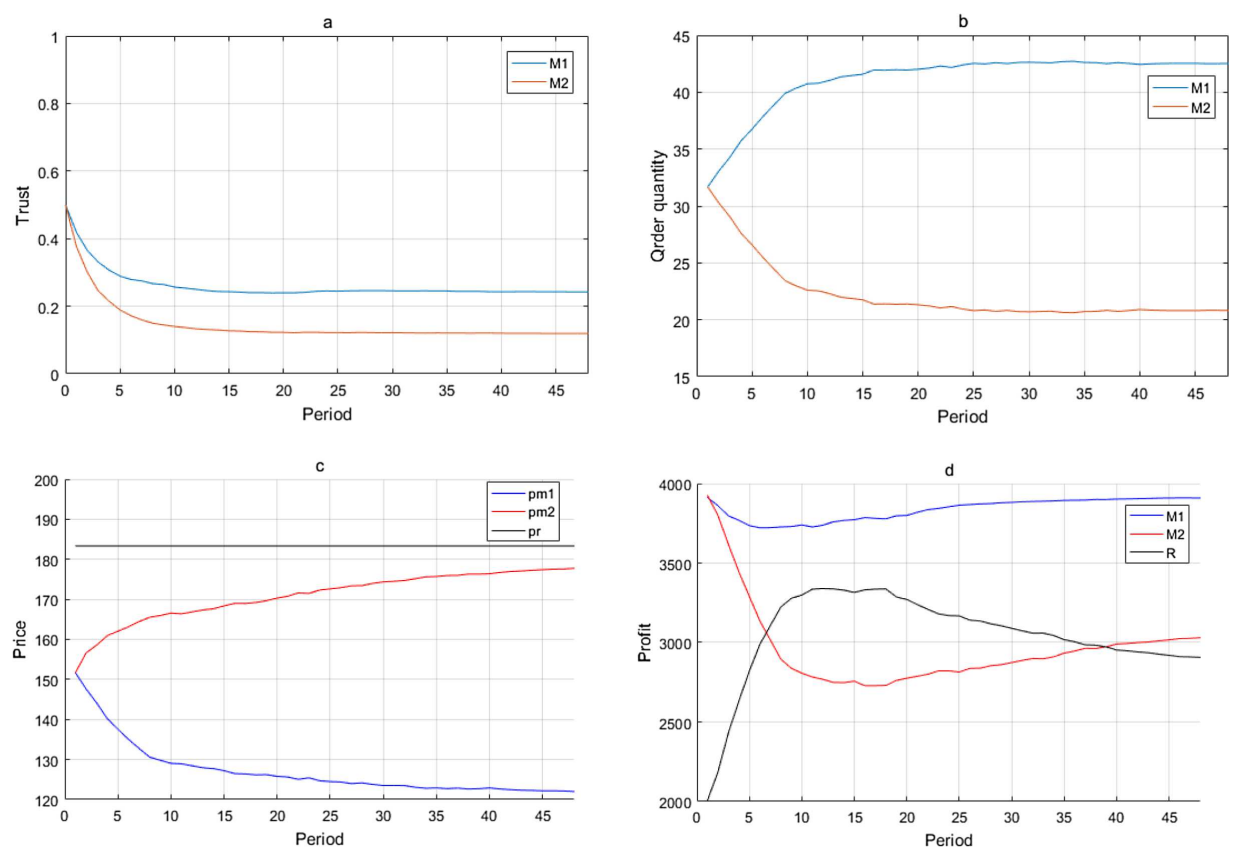

FIgURE 7. Changes in trust, order quantity, pricing, and profit when the product quality of both manufacturers is unreliable.
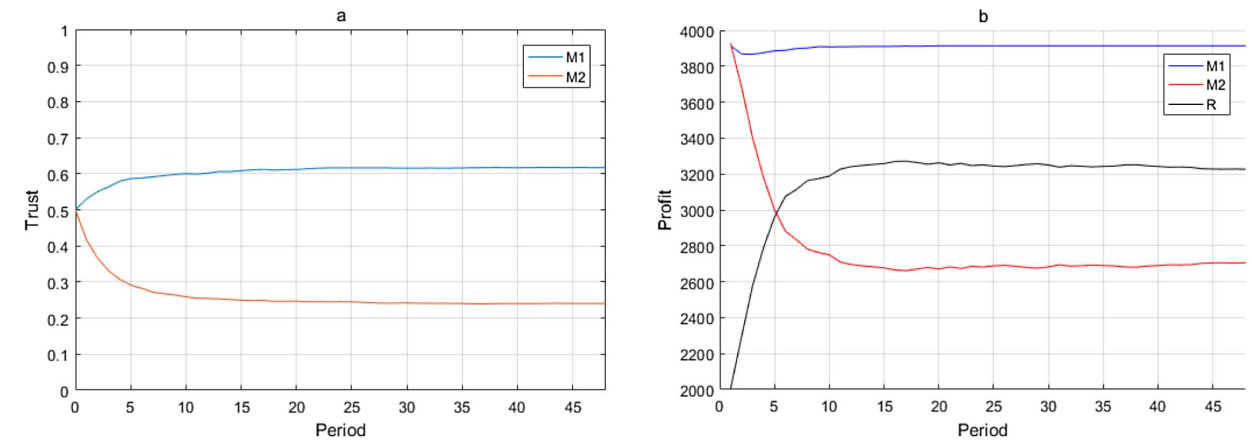

FIgURE 8. Changes in trust and profit when M1's product quality is reliable while M2's is unreliable.

\subsubsection{M1 product quality is reliable while M2 product quality is unreliable}

Set the retailer initial trust value towards two manufacturers as $T_{1,0}=T_{2,0}=0.5$; when the M1 product quality mean value is $q_{1}=16$ with the variance $\sigma_{1}^{2}=2$ and the M1 product quality mean value is $q_{2}=14$ with the variance $\sigma_{2}^{2}=2$, M1's product quality is reliable while M2's product quality is unreliable. The simulation results are shown in Figure 4. (The change in order quantity and pricing is similar to Figs. 8b and 8c and are not presented).

We can see from Figures $4 \mathrm{a}$ and $4 \mathrm{~b}$ that the retailer's trust value towards M1 increases while trust value towards M2 decreases and finally stabilizes. Figure 4d differs from Figure 3d in that M1's product quality is reliable. Although manufacturers are the leaders, the retailer's trust value towards M1 is much greater than towards M2 through the trust update mechanism. She prefers to choose M1's product with reliable quality. So 

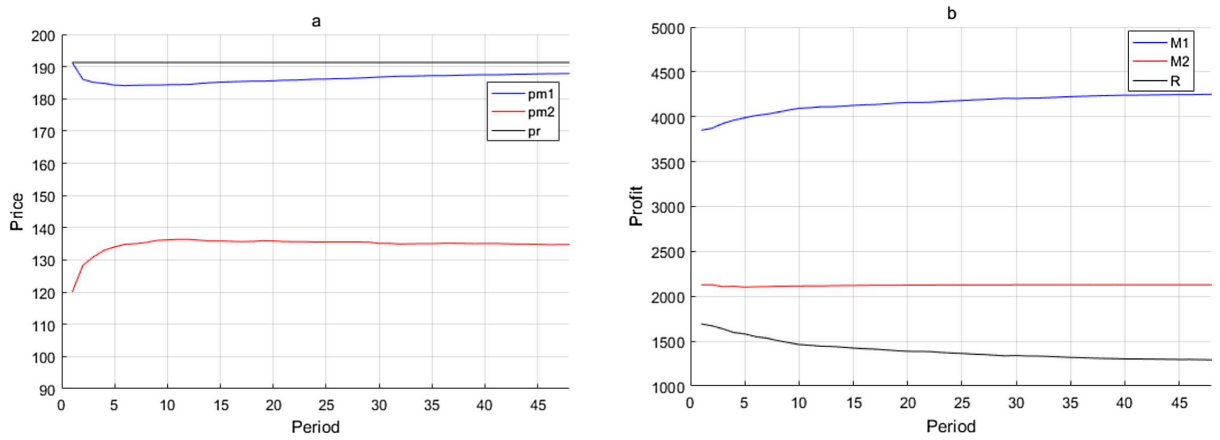

FIGURE 9. Changes in pricing and profit when the product quality of both manufacturers is reliable.

although M2 raises the wholesale price, he fails to swallow retailer revenue. The retailer's profit is higher than that of unreliable M2.

\subsection{Manufacturers are the leaders, M1 and M2 conducts a Stackelberg game}

It is assumed that the manufacturer M1 is the leader of the two manufacturers, i.e., the strength of the three roles in the supply chain is M1 $>$ M2 $>R$. Since the trend in trust value and order quantity is the same as the corresponding case in Section 6.1, it is not presented below.

\subsubsection{Product quality of both manufacturers is reliable}

The product quality of both manufacturers is relatively reliable, but M1's product quality is higher than M2. The parameter settings are the same as those in 6.1.1, and the simulation results are shown in Figure 9 below:

Observation 5.1. When manufacturers are the leaders, the manufacturer with the more reliable product is always at the top of the supply chain in terms of profits.

We can see from Figure 9 that since M1 is in a strong dominant position, he slightly reduces the wholesale price in the early stage to increase the actual order quantity and maintain the retailer's high trust value. When the transaction enters the 15th period, the retailer's trust in him stabilizes and M1 begins to gradually increase his wholesale price until it approaches the retail price, thus making his own profits far greater than other roles. M2 can only maintain his own profits by raising the wholesale price. This shows that when both manufacturers are reliable, the stronger M1 tends to suppress M2 by using the retailer's trust so that her own profit is at the top of the supply chain.

\subsubsection{Product quality of both manufacturers is unreliable}

The product quality of both manufacturers is unreliable, but the quality of M1 is relatively more reliable than that of M2. The parameter settings are the same as in 6.1.2. and the simulation results are shown in Figure 10 below.

We can see from Figure 6 that M1 lowers his wholesale price and forces M2 to increase his wholesale price to maintain profits. Since M1's product quality is relatively more reliable than M2's, the retailer increases the actual order quantity of M1 and reduces the actual order quantity of M2. Since M1 is the leader, his wholesale price can eventually come close to M2's wholesale price but is always higher. Lastly, the higher M2's wholesale price, the smaller the decline in M1's wholesale price. M2 guarantees his high wholesale price and guarantees greater profits than retailers'. The relatively reliable M1 obtains a greater actual order quantity from the retailer, making his own profit far greater than other players'. 

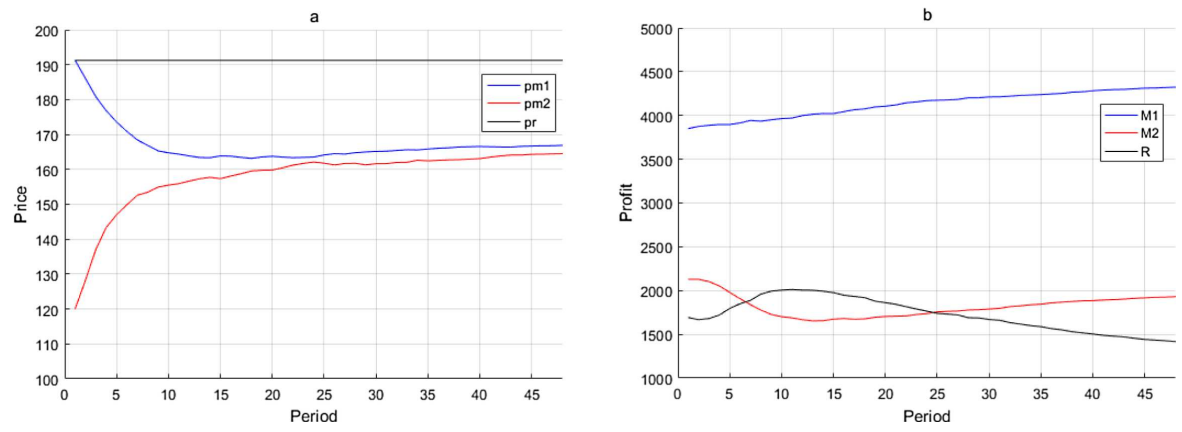

FiguRE 10. Changes in pricing and profit when the product quality of both manufacturers is unreliable.
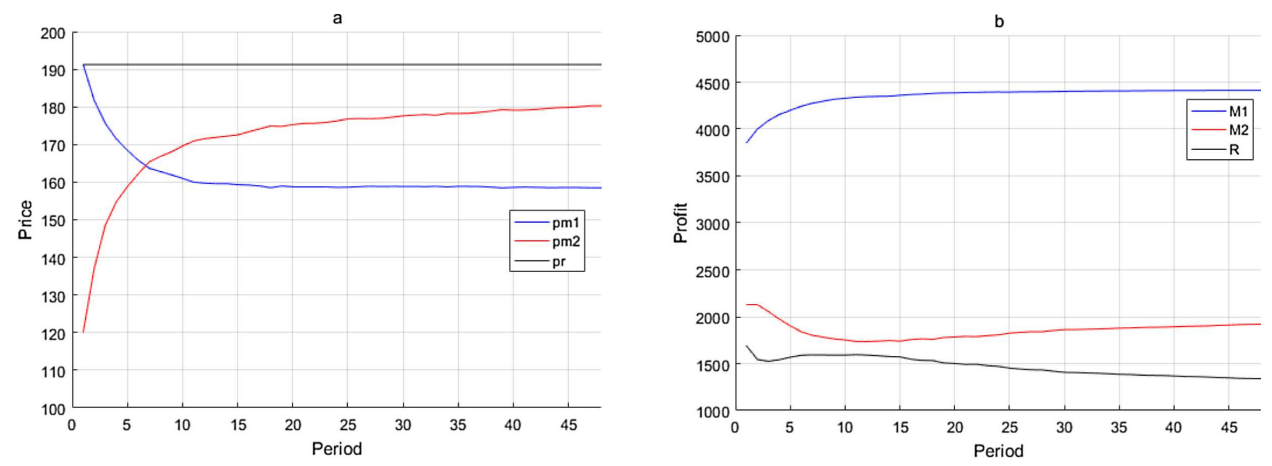

FIGURE 11. Changes in pricing and profit when M1's product quality is reliable and M2 is unreliable.

\subsubsection{M1 product quality is reliable, while M2 product quality is unreliable}

M1's product quality is reliable, while M2's product quality is unreliable. The parameter settings are the same as in 6.1.3, and the simulation results are shown in Figure 7 below:

We can see from Figure 11 that M1's product quality is more reliable and dominant than M2's and that M2 could pose no threat to M1 profit. Therefore, M1 need only appropriately lower his wholesale price to maintain a high trust value with the retailer. However, M2 is relatively more dominant than the retailer, and if he finds that the retailer is more likely to trust M1 but he cannot threaten M1 on his own, he can only significantly increase his wholesale price and squeeze retailer profit to ensure that his profits are always greater than the retailer's.

\subsubsection{M1 product quality is unreliable, while M2 product quality is reliable}

When the mean value of M1's product quality is $q_{1}=14$ with the variance $\sigma_{1}^{2}=2$, the mean value of M2's product quality is $q_{2}=16$ with the variance $\sigma_{2}^{2}=2$; i.e., M2's product quality is reliable while M1's product quality is unreliable; simulation result are shown in Figure 12 below:

Observation 5.2. If unreliable but dominant M1 competes with the reliable M2, the retailer ultimately makes more profit than the two stronger manufacturers.

We can see from Figure 8 that dominant M1, because his order quantity is reduced, finds that the retailer is more likely to trust M2 and bring his wholesale price close to the retail price. To increase the retailer's actual 

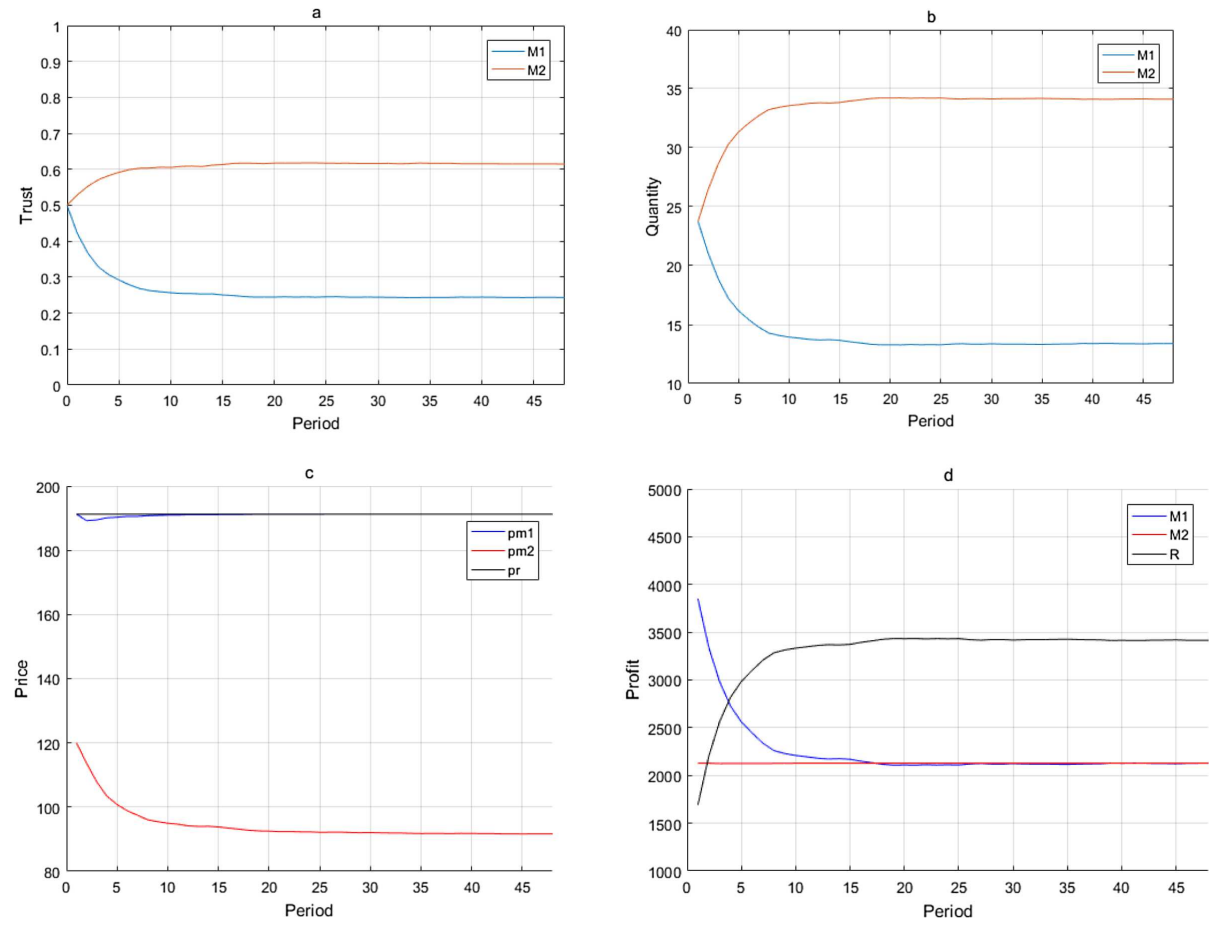

FiguRE 12. Changes in pricing and profit when M1's product quality is unreliable and M2's is reliable.

order quantity, M2 greatly reduces his wholesale price and maintains trust with the retailer while ensuring that his own profit remains unchanged. Although the wholesale price set by M1 is very high, the retailer order quantity from M1 is gradually decreases and the order quantity from M2 increases. M1's profit decreases in his competition with M2 until it finally reaches almost the same level as M2's profit. Conversely, due to the competitive behaviour of both manufacturers, the retailer expands her profits and surpasses the two stronger manufacturers to become the final winner.

In reality, on the one hand, manufacturers with high market status and good product quality will take most of profits from retailers in the same type of product, but retailers will still trust these manufacturers more because their products have better quality and can achieve good publicity effect. On the other hand, when the manufacturer take the dominant position in the supply chain, the retailer will also choose to sell products from other small manufacturers that produce the same type of product, because this can effectively prevent the product quality from falling caused by monopoly, and it can also increase the retailer's bargaining power in the supply chain so as to obtain more profits.

\subsection{The retailer is the leader, $M 1$ and $M 2$ conducts a Bertrand game}

When the retailer is the leader, we introduce a greedy function. Based on the previous parameter set and on simulation results, we find that the manufacturer's wholesale price is of the same magnitude as the order quantity; thus in the following experiment, we make the greedy coefficient $v=1$, and the other parameters are the same as in Section 5.1. The simulation result is as follows:

Comparing Figures 13a, 14a and 15a, we find that when two manufacturers are both reliable, the order quantity decline is small, but recovery is not obvious. When two manufacturers are both unreliable, the order quantity decline is huge, and recovery is obvious. 

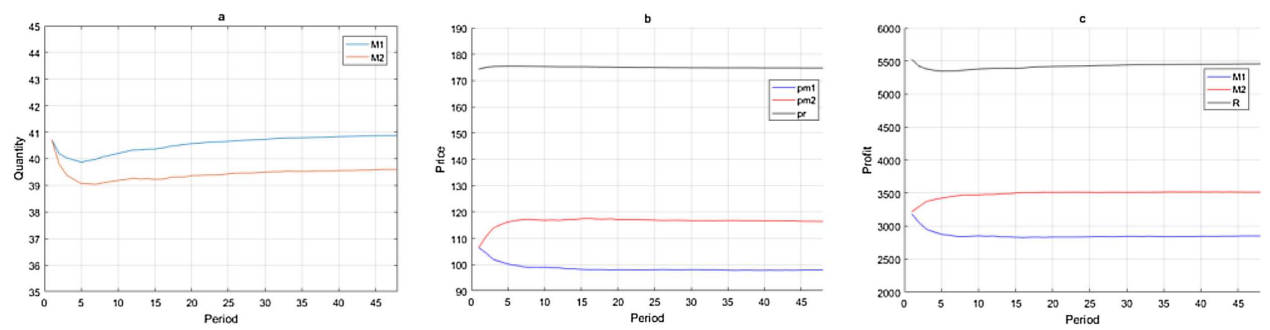

FIGURE 13. Changes in order quantity, pricing, and profit when both manufacturers' product quality is reliable.
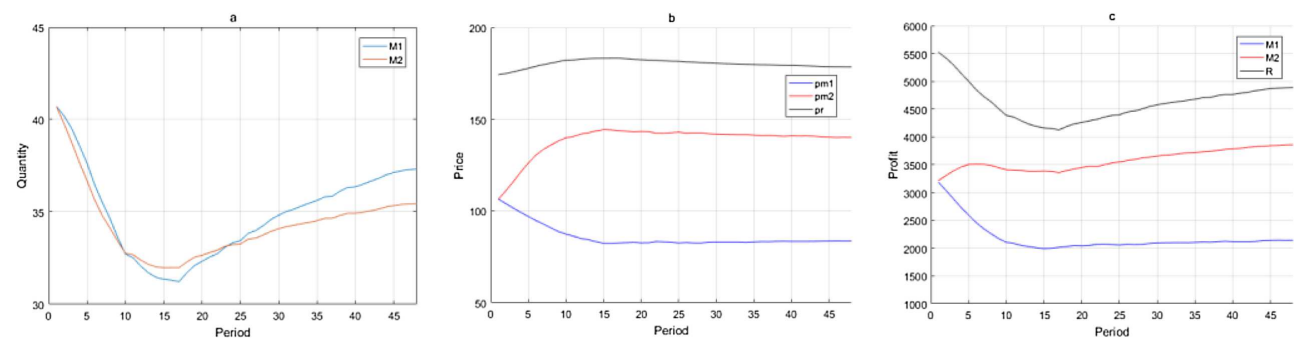

FiguRE 14. Changes in order quantity, pricing, and profit when both manufacturers' product quality is unreliable.
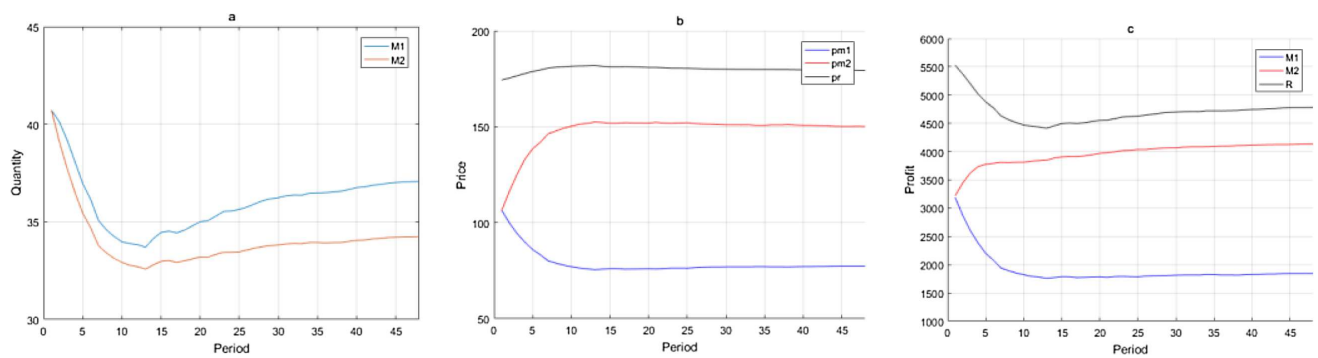

FiguRE 15. Changes in order quantity, pricing, and profit when M1's product quality is reliable and M2's is unreliable.

Observation 5.3. When the retailer is the leader, the order quantity from both manufacturers first drops and then rises, and the actual order quantity from the manufacturer with a more reliable product quality is always greater than that from the other manufacturer. Retailer profits are always at the top of the supply chain, but the manufacturer with the more reliable product quality is not as good as the other manufacturer in terms of profit.

In Figures 13-15, the retailer is the leader and M1's product quality is relatively more reliable than M2's. In the early stages of the transaction, the retailer increases her retail prices and reduces her actual order quantity in order to squeeze manufacturers' profits. M1, with more reliable product quality, believes that his high wholesale price leads to a reduction in order quantity, reduces his wholesale price. M2, with an unreliable product quality, believes that his poor quality leads to a reduction in order quantity, increases his wholesale price to maintain profits. After a certain transaction period, the retailer finds her own profit decreasing as the actual order quantity is being reduced. To increase retailer profit, she begins to increase her actual order quantity 

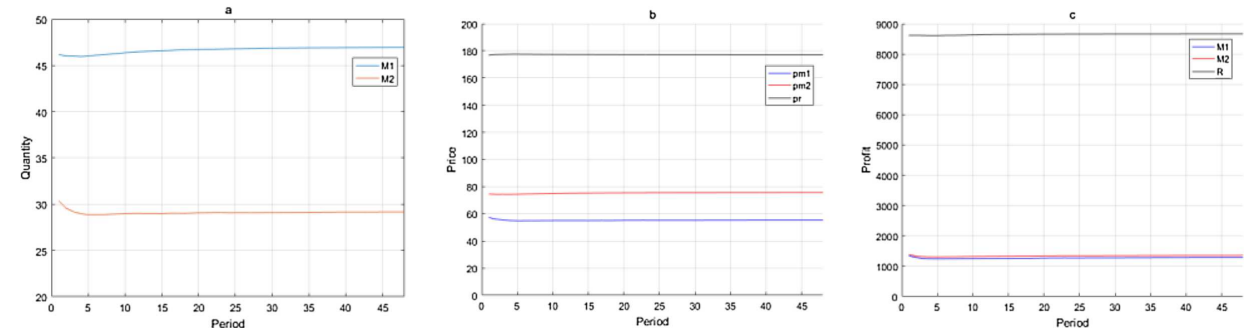

FIGURE 16. Changes in order quantity, pricing, and profit when both manufacturers' product quality is reliable.
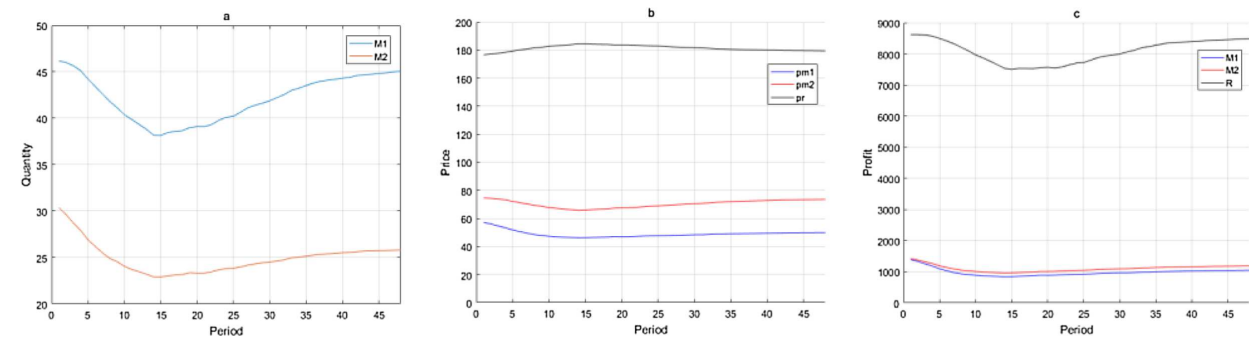

FIgURE 17. Changes in order quantity, pricing, and profit when both manufacturers' product quality is unreliable.

and maintains her retail price basically unchanged to ensure that the total market demand does not decrease. At the same time, in order to prevent M1, with his reliable quality, from discovering that his profits are being squeezed and from increasing his wholesale price after realizing that his quality is more reliable than M2's, the retailer must increase the actual order quantity from both manufacturers, although M1's order quantity, with a more reliable product quality, is greater than M2's. M2 realizes that the retailer is taking advantage of him to suppress another manufacturer after observing the increase in order quantity, so he no longer increases his wholesale prices.

Since the retailer is the leader and the manufacturers have no idea of the retailer's trust value toward them, they are utilized and squeezed by the retailer. As a result, the retailer's profit is always at the top of the supply chain. When the retailer utilizes M2 with his unreliable product quality to suppress M1 with his reliable product quality, M2 increases his wholesale prices to surpass M1 in profits with reliable product quality in the supply chain.

\subsection{The retailer is the leader, M1 and M2 conducts a Stackelberg game}

It is assumed that M1 is the leader of the two manufacturers. At this time, the strength of the three roles in the supply chain is $R>\mathrm{M} 1>\mathrm{M} 2$. Experiments are carried out according to the four situations and parameter settings in Section 5.2. The simulation results are as follows:

Observation 5.4. When the retailer is the leader and M2 is suppressed by M1, M1's order quantity is always greater than M2's, but the profits of two manufacturers are basically equal.

We can see from Figures 16-18 that when M1 is the leader of the two manufacturers, regardless of whether or not his product quality is more reliable than M2's, in order to suppress M2 and increase the retailer's actual order quantity, he always keeps the wholesale price lower than that of M2 in the transaction. If M2 in inferiority raises the wholesale price, he will be suppressed by the retailer, but if he lowers the wholesale price, he will 

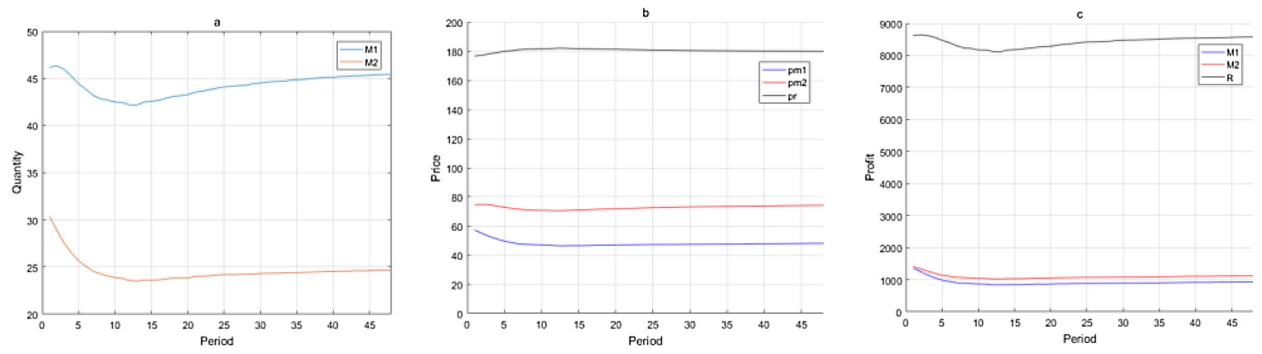

FiguRE 18. Changes in order quantity, pricing, and profit when M1's product quality is reliable and M2's is unreliable.
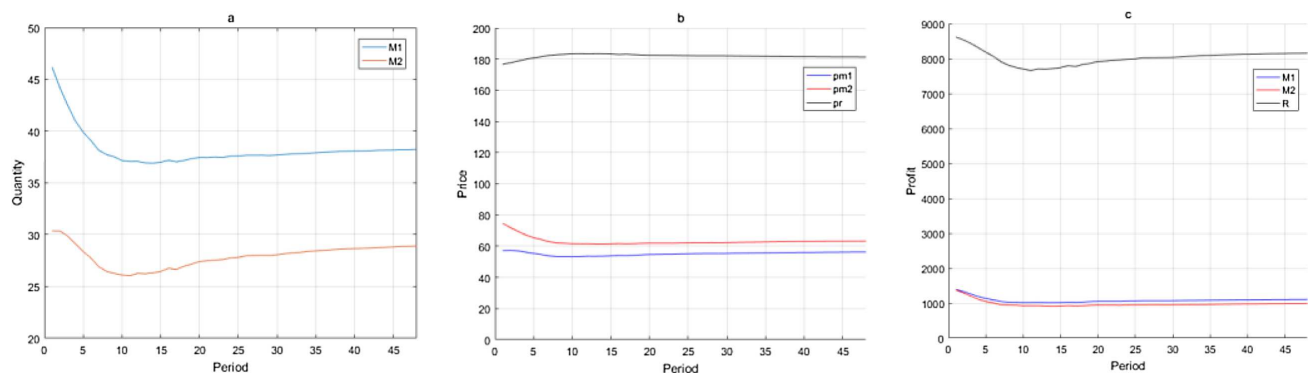

FiguRE 19. Changes in order quantity, pricing, and profit when M1's product quality is unreliable and M2's is reliable.

still be suppressed by M1, so the current wholesale price can only remain unchanged. Although M2 is always suppressed by M1, the lesser order quantity and high wholesale price strategy keep his profits in line with the stronger manufacturer M1 in the long run. The retailer no longer needs to use the relatively unreliable M2 to squeeze the profits of M1. The competition between both manufacturers is enough for the retailer to enjoy extra benefits so that the retailer's profit always remains at the top of the supply chain. Therefore, if M1 is so presumptuous as to suppress M2, this leads to a lose-lose situation,only enabling the retailer to increase her profits.

In reality, when the retailer dominates the supply chain, she tends to choose some lesser-known manufacturers. This is because the manufacturer wants the retailer to maintain a high degree of trust to him, the product quality will not be too bad; and the retailer can obtain product with lower price through competition among multiple manufacturers. For example, suppliers of Wal-Mart's private brand product GreatValue consist of a multiple of small and medium-sized manufacturing enterprises. As a result of competition among manufacturers, the product price of GreatValue is often about 30\% lower than that of similar product (Fig. 19).

\subsection{Comparisons of game modes.}

\subsubsection{Manufacturers are the leaders}

Comparing Figures 3c and 3d with Figure 5, we find that when two manufacturers conduct a Bertrand game and their initial wholesale price is equal, if the wholesale price of M1 with more reliable product quality decreases, the wholesale price of M2 increases. The two wholesale prices are negatively correlated. When both qualities are reliable, their benefits are basically the same. The retailer shows a positive correlation between their trust value and the actual order quantity. When two manufacturers compete in a Stackelberg game, if the dominant M1 is more reliable, he will resort to the retailer's trust to suppress M2 and his initial wholesale price is already higher than M2's. M2 can only squeeze retailer profits by increasing his wholesale price. The 
ultimate profits for all three parties are expressed as M1 $>$ M2 $>R$. Thus both manufacturers are eager to increase their profits by conducting a Bertrand game. When the manufacturer takes the dominant position in the supply chain, they hope to get greater bargaining power by sharing information, while the retailer hopes that two evenly matched manufacturers compete through Bertrand game. When one manufacturer is stronger, he hopes to restrict the stronger manufacturer through Stackelberg game, that is, the case in Section ??, which is more beneficial to the inferior retailer in the supply chain. In real life, a retailer has many manufacturers to provide products for it. When manufacturers have different market positions, the retailer will choose the type of manufacturer that can maximize her own interests based on trust.

\subsubsection{The retailers are leaders}

Comparing Figures 9 and 12, we find that when two manufacturers conduct a Bertrand game, the retailer confuses the manufacturer by reducing the order quantity and then recovering it. She also utilizes the relatively unreliable M2 to check and balance M1 to obtain more benefits. Manufacturers can only guess the extent to which retailers trust themselves, and change their wholesale prices, but in the end, the relatively unreliable M2 seeks benefits in the process. Thus the ultimate profits for the three parties is expressed as $R>\mathrm{M} 2>\mathrm{M} 1$. When manufacturers compete in a Stackelberg game, there is competition between manufacturers and the retailer no longer needs to utilize the unreliable M2 to seek a profit. Since M2 is suppressed by M1, the retailer need only gain extra benefits. Thus the retailer's profits in a Stackelberg game between manufacturers are generally greater than those in a Bertrand game. In real life, when the retailer is dominant in the supply chain, the retailer always hope that two manufacturers compete so that she can obtain product with lower price, and to ensure product quality through trust so that can obtain more profit.

\section{Conclusion}

In the context of two manufacturers providing same type of product to the retailer, this paper establishes a dual-tier supply chain demand and profit model and a product-based trust update model to study product quality and pricing decisions. We decide among four game models by considering two situations, i.e., manufacturerdominant and retailer-dominant scenarios, and resort to a Bertrand game and a Stackelberg game respectively in order to derive the corresponding optimal pricing strategy. The rationality of the trust update model and the impact of the increase, decrease and time parameters of trust on the optimal results are also given.

The main findings of this paper are as follows:

(1) When manufacturers are the leaders, the manufacturer with more reliable product quality is always at the top of the supply chain in terms of profit. However, if M1 with unreliable product quality is the leader and competes with M2 with reliable product quality, this eventually causes the retailer's profit to surpass that of both stronger manufacturers.

(2) When two manufacturers conduct a Bertrand game, retailers have a positive correlation between their trust value and the actual order quantity. When the two manufacturers compete in a Stackelberg game, the dominant M1 tends to suppress M2 by means of the retailer's trust. The initial wholesale price is already higher than M2's, and M2 can only make a profit by squeezing the retailer's profit.

(3) When the retailer is the leader, the order quantity of both manufacturers first drops and then recovers, and the actual order quantity for the manufacturer with the more reliable product quality is greater than that of the other manufacturer. The profit of the manufacturer with the more reliable product quality is worse than the other manufacturer's. In particular, when M1 is the leader and M2 is suppressed by M1, the order quantity for M1 is always greater than that of M2.

(4) When two manufacturers conduct a Bertrand game, the retailer utilizes M2, with a relatively unreliable product quality, to check and balance M1. Manufacturers can only guess the extent to which retailers trust themselves in order to change their wholesale prices, but in the end, unreliable M2 seeks more benefits. When the two manufacturers compete in a Stackelberg game, given the competition between the two 
manufacturers, the retailer no longer needs to make a profit by utilizing M2. She only needs to gain extra profit, as M2 is suppressed by M1.

The results of this paper show that the multi-manufacturer product quality and price competition model based on the retailer's trust update under the multi-period transaction can fundamentally understand the influence of trust level of manufacturer's product quality and channel, and market power structure on the pricing strategy and maximum profit of two products of same type with slightly different qualities in the multi-manufacturerretailer supply chain. This research is conducted with certain assumptions on linear demand and supply chain situations. However, the supply chain situation is diverse, and the research can be extended to more explorations in future. For example, the market demand can be formulated as non-linear or random functions. More case studies respecting to different supply chain situations (e.g., competitions among supply chains, limited capacity in production, irrational decision makers, etc.) potentially drive more observations.

Acknowledgements. This research was funded by the National Natural Science Foundation of China (Nos. 71802065, 71501128, 71632008, 71871105, 71874109), Soft Science Research Project of Zhejiang Province (No. 2021C35052), Zhejiang Statistical Research Project (No. 20TJQN10), Zhejiang Provincial Natural Science Foundation (No. LQ18G010003) and Humanities and Social Science Fund of Ministry of Education of China (No. 20YJC630033). The central government of zhejiang province guides local science and technology development projects (No.2020ZY1010).

\section{REFERENCES}

[1] R.D. Banker, I. Khosla and K.K. Sinha, Quality and competition. Manage. Sci. 44 (1998) 1179-1192.

[2] A. Banu and S.K. Mondal, Analyzing an inventory model with two-level trade credit period including the effect of customers' credit on the demand function using $q$-fuzzy number. Oper. Res. 20 (2020) 1559-1587.

[3] G.G. Cai, Z.G. Zhang and M. Zhang, Game theoretical perspectives on dual-channel supply chain competition with price discounts and pricing schemes. Int. J. Prod. Econ. 117 (2009) 80-96.

[4] T. Chakraborty, S.S. Chauhan and M. Ouhimmou, Cost-sharing mechanism for product quality improvement in a supply chain under competition. Int. J. Prod. Econ. 208 (2019) 566-587.

[5] J. Chen, L. Liang, D.Q. Yao and S. Sun, Price and quality decisions in dual-channel supply chains. Eur. J. Oper. Res. 259 (2017) 935-948.

[6] Z. Cheng, J. Xiao and K. Xie, Optimal product quality of supply chain based on information traceability in fashion and textiles industry: an adverse logistics perspective. Math. Prob. Eng. 2013 (2013) 87-118.

[7] J.K. Dey, S.K. Mondal and M. Maiti, Two storage inventory problem with dynamic demand and interval valued lead-time over finite time horizon under inflation and time-value of money. Eur. J. Oper. Res. 185 (2008) 170-194.

[8] Digital Commerce, US ecommerce sales grow 14.9\% in 2019 (2020). Available at https://www.digitalcommerce360.com/ article/us-ecommerce-sales/.

[9] B. Dong, W. Tang and C. Zhou, Strategic sourcing under recall loss sharing and product quality investment. RAIRO:OR 54 (2020) 1133-1160.

[10] R. Dubey, A. Gunasekaran, S.J. Childe, T. Papadopoulos, C. Blome and Z. Luo, Antecedents of resilient supply chains: an empirical study. IEEE Trans. Eng. Manage. 66 (2019) 8-19.

[11] N. Ebrahim-Khanjari, W. Hopp and S.M.R. Iravani, Trust and information sharing in supply chains. Prod. Oper. Manage. 21 (2012) 444-464.

[12] S.A. Edalatpanah, On the preconditioned projective iterative methods for the linear complementarity problems. RAIRO:OR 54 (2020) 341-349.

[13] X. Fu and G.H. Han, Trust-embedded information sharing among one agent and two retailers in an order recommendation system, Sustainability 9 (2017) 710.

[14] X. Fu, M. Dong, S.X. Liu and G.H. Han, Trust based decisions in supply chains with an agent. Decis. Support Syst. 82 (2015) $35-46$.

[15] X. Fu, M. Dong and G.H. Han, Coordinating a trust-embedded two-tier supply chain by options with multiple transaction periods. Int. J. Prod. Res. 55 (2017) 2068-2082.

[16] G. Gao, B.N. Greenwood, R. Agarwal and J.S. McCullough, Vocal minority and silent majority: how do online ratings reflect population perceptions of quality? MIS Quart. 39 (2015) 565-589.

[17] Q. Gen and S. Mallik, Inventory competition and allocation in a multi-channel distribution system. Eur. J. Oper. Res. 182 (2007) 704-729.

[18] B.C. Giri, C. Mondal and T. Maiti, Optimal product quality and pricing strategy for a two-period closed-loop supply chain with retailer variable markup. RAIRO:OR $\mathbf{5 3}$ (2019) 609-626.

[19] H. Gurnani, M. Erkoc and Y. Luo, Impact of product pricing and timing of investment decisions on supply chain coopetition. Eur. J. Oper. Res. 180 (2007) 228-248. 
[20] G. Han and M. Dong, Trust-embedded coordination in supply chain information sharing. Int. J. Prod. Res. 53 (2015) $5624-5639$.

[21] G. Han and S. Yan, Does food safety risk perception affect the public's trust in their government? An empirical study on a national survey in China. Int. J. Environ. Res. Pub. Health 16 (2019) 1874.

[22] H. Jafari, S.R. Hejazi and M. Rasti, Pricing decisions in dual-channel supply chain with one manufacturer and multiple retailers: a game-theoretic approach. RAIRO:OR 51 (2017) 1269-1287.

[23] S.A. Johnson and M.B. Houston, Buyer-supplier contracts versus joint ventures: determinants and consequences of transaction structure. J. Mark. Res. 37 (2000) 1-15.

[24] B. Khara, J.K. Dey and S.K. Mondal, Effects of product reliability dependent demand in an EPQ model considering partially imperfect production. Int. J. Math. Oper. Res. 15 (2019) 242-264.

[25] H.L. Lee, K. So and C.S. Tang, The value of information sharing in a two level supply chain. Manage. Sci. 46 (2000) 626-643.

[26] J. Ma and Q. Li, The complex dynamics of Bertrand-Stackelberg pricing models in a risk-averse supply chain. Disc. Dyn. Nat. Soc. 4 (2014) 1-14.

[27] A.K. Manna, J.K. Dey and S.K. Mondal, Imperfect production inventory model with production rate dependent defective rate and advertisement dependent demand. Comput. Ind. Eng. 104 (2017) 9-22.

[28] A.K. Manna, J.K. Dey and S.K. Mondal, Effect of inspection errors on imperfect production inventory model with warranty and price discount dependent demand rate. RAIRO:OR 54 (2019) 1189-1213.

[29] T. Maiti and B.C. Giri, A closed loop supply chain under retail price and product quality dependent demand. J. Manuf. Syst. 37 (2015) 624-637.

[30] Ö. Özer and Y. Zheng, Trust in forecast information sharing. Manage. Sci. 57 (2011) 1111-1137.

[31] K. Özpolat and W. Jank, Getting the most out of third party trust seals: an empirical analysis. Decis. Support Syst. 73 (2015) $47-56$.

[32] State Council of China, China's retail sales up $8 \%$ in 2019 (2020). Available at http://english.www.gov.cn/archive/ statistics/202001/17/content_WS5e211f9cc6d0891feec027bf.html.

[33] A. Taleizadeh, M. Moshtagh and I. Moon, Pricing, product quality, and collection optimization in a decentralized closed-loop supply chain with different channel structures: game theoretical approach. J. Clean. Prod. 189 (2018) $406-431$.

[34] J.Y. Tsai, S. Egelman, L. Cranor and A. Acquisti, The effect of online privacy information on purchasing behavior: an experimental study. Inform. Syst. Res. 22 (2011) 254-268.

[35] A.A. Tsay and N. Agrawal, Channel dynamics under price and service competition. Manuf. Serv. Oper. Manage. 2 (2000) $372-391$.

[36] J.M. Villas-Boas, Product line design for a distribution channel. Mark. Sci. 17 (1998) 156-169.

[37] G. Xie, W. Yue, S. Wang and K.L. Kin, Quality investment and price decision in a risk-averse supply chain. Eur. J. Oper. Res. 214 (2011) 403-410.

[38] K. Zhu, R.Q. Zhang and F. Tsung, Pushing quality improvement along supply chains. Manage. Sci. 53 (2007) $421-436$. 